\title{
The Good News and the Bad News about Long-Run Stock Market Returns*
}

\author{
Donald Robertson and Stephen Wright \\ Faculty of Economics and Politics \\ University of Cambridge \\ Cambridge CB3 9DD \\ e-mail: stephen.wright@econ.cam.ac.uk
}

September 24, 1998

\begin{abstract}
If stock prices followed a random walk, uncertainty about future stock prices would be so great that the observed bias towards equities in longterm investment portfolios would be surprising. The good news is that if, as a growing body of research suggests, there is even a weak tendency for stationary valuation indicators to predict future stock prices, long-run returns can become markedly more predictable. We illustrate this in a cointegrating VAR, with Tobin's $q$ as one of the cointegrating relations. The bad news is a corollary of the good news: $q$ and most other indicators point to massive overvaluation at end-1997, and hence the prospect of weak stock prices well into the next century.
\end{abstract}

*We thank Andrew Smithers for the crucial role he played in stimulating and helping to develop this research. We are grateful to Smithers \& Co, and Arbor Trading, Chicago, for provision of data. We also thank Steve Satchell and Yongcheol Shin for helpful discussions. 


\section{Contents}

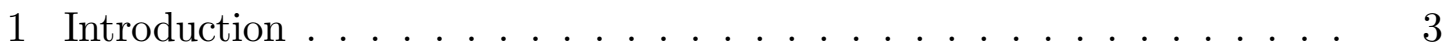

2 Can Stock Markets be Valued? . . . . . . . . . . . . . . . . . 5

3 Tobin's $q$ as a Valuation Criterion . . . . . . . . . . . . . 7

3.1 The Rationale for Tobin's $q \ldots \ldots \ldots$. . . . . . . 7

3.2 Data .......................... 8

3.3 Univariate Properties of $q \ldots \ldots \ldots$. . . . . . . . . . . . . . . . . . . . . . . . . . .

4 Tobin's $q$ in a Cointegrating VAR . . . . . . . . . . . . . . . . . . . . . 12

4.1 Data Definitions and Univariate Properties . . . . . . . . . . . 12

4.2 The Reduced Rank VAR Representation . . . . . . . . . . . . . . 12

4.3 Tests of Granger Causality . . . . . . . . . . . . . . . . . . . . . 14

4.4 Monte Carlo Analysis . . . . . . . . . . . . . . . . . . . . . 14

4.5 Stock Price Forecast Variance in a Cointegrating VAR . . . . . . 15

5 Comparing Confidence Intervals from the Cointegrating VAR and the Random Walk in Normal Circumstances: The Good News About LongRun Stock Market Returns . . . . . . . . . . . . . . . . . . . . . . . . 18

6 .... But Circumstances are Far from Normal: The Bad News About Long-Run Stock Market Returns . . . . . . . . . . . . . . . . . 20

7 What do our Results Tell Us About Market Efficiency? . . . . . . . . . 22

8 Conclusions . . . . . . . . . . . . . . . . 25

A Data Sources and Construction . . . . . . . . . . . . . . 27

A.1 Capital Stock and Tangible Assets . . . . . . . . . . . . . . . . . 27

A.2 Corporate Financial Assets and Liabilities . . . . . . . . . . . . . 28

A.3 Market Value of Equities . . . . . . . . . . . . . . . . . . . . . . . 28

B Monte Carlo Analysis . . . . . . . . . . . . . . . . . . . . . . . 29

C Calculation of Forecast Variance in a Cointegrated VAR . . . . . . . 30

D Tables and Charts . . . . . . . . . . . . . . . . . . 33 


\section{Introduction}

How risky are stocks and shares as long-term investments?

In the textbook efficient market, the answer is a fairly simple one. Having identified an efficient market portfolio, the return on this portfolio will be a random variable, innovations to which will be orthogonal to the available information set. The riskiness of this return is captured by its associated instantaneous volatility, $\sigma$, which can, with modest difficulty, be estimated from available data. The variance of the return over any given horizon $h$ will then be the product of $h$ and $\sigma^{2}$. If $\sigma$ is time-varying, the procedure is technically somewhat more complicated, but is essentially the same.

To most practitioners - stockbrokers, pension fund managers or the like - the answer also appears fairly simple. The consensus view - as evidenced both by word and deed - is that any investment portfolio with a long-run orientation should have a strong bias to equities. The proportion of stocks held by a typical pension fund US has been running at around 70\% in recent years. ${ }^{1}$ Shiller (1998) and Kon-Ya, Tsutsui and Shiller (1998) report survey evidence that this behaviour appears to be consistent with the views of both investment professionals and wealthy investors. The assumption that stocks are the dominant long-run asset has been defended, most evidently in the work of Siegel (1994), not just on the familiar grounds of superior returns, but also on the grounds of relative predictability. Comparing returns on stocks, bonds and bills over nearly 200 years of US data, Siegel suggests that the degree of unpredictability of stock market returns is barely, if at all, greater than that of bonds and bills, over investment horizons of twenty to thirty years.

Whilst these two answers might in principle be mutually consistent, they are very hard to reconcile on the basis of available observations of actual stock markets. The problem, in essence, is that any reasonable estimate of $\sigma$, fed into a random walk stock market, implies returns which would seem to be simply too risky to be consistent with the practioners' view. To illustrate this with a simple statistic: if real returns are normally distributed around their historic mean, the random walk model would imply, given historic average values of $\sigma$, that over a twenty year horizon there is a probability of over $30 \%$ that an investor in the US

\footnotetext{
${ }^{1}$ Estimate derived as (corporate equities plus mutual fund shares)/ (total financial assets less miscellaneous assets), for private pension funds, as of end-1997 (Source: Federal Reserve, 1997, Table L119.
} 
stock market will realise a real capital loss. ${ }^{2}$ This degree of uncertainty certainly appears inconsistent with Siegel's (op cit) claims; it would also be surprising if practitioners had such a strong preference for stocks if they perceived them to be as risky as this, especially given the fact that in recent years it has become possible to achieve respectable, and entirely safe long-horizon returns, via indexed bonds.

But a growing body of literature has in recent years cast doubt on the random walk representation of efficient markets. Shiller(1981) initiated a literature which suggests that both stocks and bonds are excessively volatile in relation to the underlying uncertainty of their fundamentals; ${ }^{3}$ variance ratio tests have suggested that long-horizon variances are lower than the random walk model would predict (Poterba \& Summers, 1988); and a wide body of research has shown that there is a degree of predictability in stock market returns, especially over long horizons (Breen, Glosten \& Jagannathan (1989); Jegadeesh (1990); Bekaert \& Hodrick (1992); Ammer \& Campbell (1993); Chiang, Liu \& Okunev (1995); Pesaran \& Timmermann (1995); Campbell \& Shiller (1998)). ${ }^{4}$

Much of the evidence for predictive power has arisen from the ability of various valuation measures to predict (if only weakly) subsequent stock market returns. This paper shows that, under certain conditions and circumstances, exploiting the predictive power of a well-chosen valuation criterion can significantly reduce the uncertainty associated with long-run stock market returns. We assume that any useful valuation criterion can be expressed as the ratio of the stock price to some measure of the fundamental. If stock prices are volatile (possibly excessively so), but have a tendency, however weak, to revert towards a fundamental which may be easier to predict, at least some of the predictability of the fundamental will be passed on to stock prices. The unconditional volatility of stock returns will thus overstate uncertainty over long horizons - possibly significantly so.

For reasons expanded on in a later section we opt for a valuation criterion which has not thus far received much attention - Tobin's $q .^{5}$ Using $q$ as a cointe-

\footnotetext{
${ }^{2}$ At current levels of the dividend yield, a zero real capital gain would imply a total real return roughly equivalent to the historic average real return on treasury bills. Note that the widening of forecast variance is worsened further once allowance is made for parameter uncertainty in the drift - see Section 4.5.

${ }^{3}$ This finding appears to be robust to qualifications of Shiller's original methodology - see DeBondt \& Thaler (1985); Chopra, Lakonishok \& Ritter (1992).

${ }^{4}$ For an excellent survey of this field, see Chapters 1,2 and 7 of Campbell, Lo and MacKinlay (1997).

${ }^{5}$ An exception is Kopcke(1997), but there is also an obvious link wth the use of book-
} 
grating relation in a vector autoregressive representation, we show that confidence intervals in predicting long-run stock market returns can be very significantly reduced, compared to those from a simple random walk model, to the extent that the practitioners' preference for equities becomes understandable, in normal circumstances. This is the good news about long-run stock market returns.

The bad news about long-run stock market returns is a corollary of the good news. Tobin's $q$ (and other valuation criteria) help reduce uncertainty about stock market returns by their ability to predict above-average returns when $q$ is below average, and below-average returns when it is above average. As of end-1997, the latter was the relevant case: indeed $q$ indicated a degree of overvaluation comparable only to that seen before the crash of late-1929. The implication is that, even after adjusting for both parameter and model uncertainty, there is a high probability of a cumulative real decline in the stock market over the first decades of the 21st Century.

\section{Can Stock Markets be Valued?}

The notion that markets can be valued must, if it is to be at all interesting, imply the possibility that they can at times be over- or undervalued. This in turn must, of necessity imply a rejection of at least the semi-strong version of the random walk representation of the efficient markets hypothesis (that stock price innovations are orthogonal to publicly available information).

The concept of the efficient market which underlies the random walk representation defines a world in which markets are always, by definition, fairly valued, given the information set available to participants in the market. In such a world it would of course be possible in principle to claim that a market was under- or overvalued, but such a claim would be of no practical use. Given the usual efficient market assumptions, any information about the future relevant to market prices should already be incorporated in those prices. Valuation of a market must, if it is to be of any practical use, imply something about the future of that market. If it is alleged that a market is, for example, overvalued, this must imply a prediction that, over some horizon, returns are going to be subnormal. Clearly, this cannot be consistent with the random walk hypothesis. ${ }^{6}$ A simple example helps

to-market ratios in the cross-sectional excess return literature initiated by Fama and French (1992).

${ }^{6}$ In Section 7 we discuss whether it can be consistent with a less restrictive concept of efficiency. 
to illustrate this point, and bring out the crucial empirical characteristics of any useful indicator .

Suppose that some valuation criterion, $V$ is proposed, which is claimed to be an indicator of whether the stock market is overvalued, and that this ratio can be expressed as the ratio of the real stock price $P$, to an indicator of what (without necessarily implying any very deep meaning thereby) we shall refer to as the "fundamental", $F$. This characteristic is certainly shared by most commonly used valuation criteria, and, indeed, would appear to be a crucial property, if there is any intention to quantify the degree of overvaluation. Suppose further that the two underlying series can be given the following log-linear first order error correction representation (with lower case letters representing logs of underlying series):

$$
\begin{aligned}
& \Delta p_{t}=\alpha_{o}+\alpha_{1} v_{t-1}+\varepsilon_{t}^{p} \\
& \Delta f_{t}=\beta_{o}+\beta_{1} v_{t-1}+\varepsilon_{t}^{f}
\end{aligned}
$$

In such a representation, $v\left(\equiv p_{t-1}-f_{t-1}\right)$ is the cointegrating relation between two non-stationary series, $p$ and $f$. If both series contain a single unit root, a necessary condition, therefore, for $V$ to be a useful valuation criterion, is that it must be a stationary process. This is however not a sufficient condition. Stationarity of $v$, and hence cointegration of $p$ and $f$, could in principle be possible in an efficient market, if $\alpha_{1}$ equalled zero. In this case, the stock price would be an independent random walk, and there would be one way Granger Causality from the stock price to the "fundamental". $V$ would simply be an indicator of future changes in $F$, and would not be a useful valuation criterion. The second crucial condition for any useful criterion must therefore be that it must Granger-Cause the stock price - in the above representation, $\alpha_{1}$ must be non-zero. The necessary link between the use of any valuation criterion and rejection of the random walk hypothesis is therefore clear-cut. ${ }^{7}$

\footnotetext{
${ }^{7}$ This argument is in essence very similar to that of Campbell and Shiller (1998), though the argument in that paper is not couched in terms of cointegration. It is not our intention in this paper to provide a rationale for such a rejection of the random walk hypothesis (although below, in Section 7, we discuss some possible explanations). At this stage we simply take the not inconsiderable empirical evidence of the limitations of the random walk model as given, and note the necessary link between any proposed valuation criterion and the central implication of this literature.
} 
There is a third characteristic which, whilst not strictly essential, is clearly desirable. Any useful valuation criterion should ideally have a fundamental which is "smooth": that is, it should be easy to forecast, most especially over long horizons. We discuss this characteristic in more detail below, in Section 4.5.

Given the limitations of empirical evidence, however, it is also very important that we should be able to justify any valuation criterion on theoretical grounds. An attraction of our chosen indicator, Tobin's $q$, is that, as we show below, it not only satisfies the two empirical properties proposed above (and surprisingly few of the commonly proposed alternative valuation criteria actually do), but is also arguably the most robust, and best grounded, in theoretical terms.

\section{Tobin's $q$ as a Valuation Criterion}

\subsection{The Rationale for Tobin's $q$}

One attraction of the use of Tobin's $q$ as a valuation criterion is its generality. As originally formulated in Tobin (1969), the rationale for mean reversion of $q$ is essentially a long-run arbitrage relationship: a deviation of $q$ from its equilibrium value (which should in theory be unity) implies that the returns on existing capital, purchased in the stock market, differ from those on new capital. ${ }^{8}$ Whilst subsequent research has largely focused on investment in fixed capital as the mechanism which exploits this arbitrage opportunity, the arbitrage condition itself, like all arbitrage conditions, is independent of the mechanism which brings it about.

As an arbitrage relationship, $q$ is arguably of more general applicability, in principle, than the two more commonly used valuation criteria: the price-earnings multiple and the dividend yield. Whilst both have been shown to have predictive power for stock prices on available historic data, and both can also be defended on theoretical grounds, these are arguably not as robust as is the rationale for $q$.

A central assumption underlying the use of both the dividend yield and the $\mathrm{P} / \mathrm{E}$ multiple (and hence, by implication, its reciprocal, the earnings yield) is that the expected return of the representative investor is a stationary process. This assumption, whilst it may appear to have some empirical foundation, is nonetheless a strong one. In addition if earnings and dividends are $\mathrm{I}(1)$ processes, this will imply that both the dividend yield and the $\mathrm{P} / \mathrm{E}$ will also be stationary (Campbell, Lo and Mackinlay, 1997).

\footnotetext{
${ }^{8}$ In principle this is a marginal relationship, but Hayashi (1982) shows that under reasonable conditions average and marginal $q$ will coincide.
} 
For the $\mathrm{P} / \mathrm{E}$ multiple, empirical evidence appears consistent with both assumptions (Campbell \& Shiller (1998), Siegel $\left.(1994)^{9}\right)$; but, logically, a permanent change in the discount rate would imply a permanent change in the $\mathrm{P} / \mathrm{E}$. The dividend yield can be subjected to the same criticism, but its steady-state value will in addition be affected by changes in the payout ratio - this additional factor indeed appears to have been of some importance not only in theory but also empirically. ${ }^{10}$

In contrast, stationarity of $q$ requires minimal assumptions about the nature of equilibrium: it simply implies a steady-state relationship between two rates of return, without requiring any knowledge of the steady-state values of the returns themselves.

\subsection{Data}

Full details of data construction are provided in Appendix $A$. We have a consistent source for all data from 1945 to 1997, in the flow of funds tables for non-financial corporations published by the Federal Reserve (Federal Reserve, 1998) . Between 1925 and 1944, we extrapolate series backwards using available data from the BEA for tangible assets (Bureau of Economic Analysis,1997) and the national accounts (Bureau of Economic Analysis, 1992) and a privately supplied series for the market value of equities. Apart from our use of this latter series, our methodology is very similar to Blanchard et al (1993), and, when using similar definitions, produces very similar characteristics.

Our only departure is in our definition of $q$. Tobin's original definition (followed in most academic work) is

$$
q=\frac{P \cdot E+L}{K}
$$

\footnotetext{
${ }^{9}$ Consistency with empirical evidence of the assumption that the expected return is stationary cannot logically be inferred solely from the stationarity properties of the $\mathrm{P} / \mathrm{E}$ in isolation. Siegel's (op. cit.) evidence on very long-run investor returns is however suggestive of these being stationary, although he performs no formal tests.

${ }^{10}$ The observation that, over long samples, the payout ratio appears to have a unit root must imply that the $\mathrm{P} / \mathrm{E}$ multiple and the dividend yield cannot both be stationary processes - the empirical evidence strongly suggests that over the same long samples it is the dividend yield which is nonstationary (using the term loosely, to encompass a broad range of possible forms of difficulties in forecasting over long horizons, which may in principle be represented by, for example, unpredictable, but bounded, structural breaks).
} 
where $P$ is the stock price, $E$ is the number of shares ${ }^{11}, L$ is the market value of liabilities, and $K$ is corporate assets. We prefer to follow the Federal Reserve's practice in using the following ratio ${ }^{12}$

$$
q=\frac{P \cdot E}{K-L}
$$

where the denominator is corporate net worth. It can readily be seen that this definition has the same properties, with respect to the sign of derivatives to its components, as Tobin's original definition, and indeed, as we show below, in terms of their statistical properties the two ratios look extremely similar. Our preference for the second definition however, is for two reasons.

First, the original definition is predicated, implicitly, on a world in which the Miller-Modigliani theorem holds. Whilst this may approximately be the case, we would not wish to take this assumption for granted, especially given the clear link, already noted, between the use of any valuation criterion, and an implicit rejection of perfectly efficient markets.

Our second reason is more pragmatic. Since our focus is on the stock market, rather than on a combination of the equity and bond markets, our preferred definition, (3.2), fits more easily into the framework outlined in Section 2, since it can be easily broken down into two terms, in price, and in the implicit "fundamental", $\frac{K-L}{E}$, of corporate net worth per share. Thus, if, other things equal, the stock price falls by $x \%$, our measure of $q$ also falls by $x \%$; the original definition will fall by a lesser percentage, depending on the relative magnitude of the stocks of bonds and equities. ${ }^{13}$

In order to ensure consistency of our definition throughout the sample period, we use a definition of $K$ which excludes land and residential capital, since this component of total corporate assets is not available before 1945. In practice, however, even in the published figures for later periods data for land is highly

\footnotetext{
${ }^{11}$ We derive this series by dividing the Federal Reserve series for the market value of equities outstanding by our chosen measure of $P$ : the $\mathrm{S} \& \mathrm{P}$ Industrials Index. There is clearly an implicit measurement error here, since the Fed figure relates to all nonfinancial corporations, but there is no obvious alternative to this approach.

${ }^{12}$ It should be noted that whilst the Federal Reserve publishes this ratio on a regular basis, it does not refer to it as $q$. This is our own innovation, for which we beg indulgence from Professor Tobin.

${ }^{13}$ This property is also particularly useful when we come to embed $q$ in a loglinear cointegrating vector autoregression, since it implies a simple restriction on the cointegrating vectors, which would be impossible using the original definition.
} 
imperfect: indeed there is a distinct discontinuity in the Fed's methodology before and after 1989 (for details, see Appendix $A$ ), so that our methodology is arguably more robust even after 1945 .

\subsection{Univariate Properties of $q$}

Chart 1 shows two series for $q$, constructed using the definition given in (3.2), differing only due to the inclusion and exclusion of land and nonresidential capital. The chart shows that, for most of the common sample, from 1945 onwards, the different definition has little impact. Only more recently (most notably after the change in methodology in 1989) do the series diverge somewhat.

Chart 2 shows, for comparison, a measure of $q$ constructed from the same data sources, using Tobin's original definition in (3.1a). It is clear that the nature of the resulting series is very similar, whichever definition is used. For comparison, the chart also shows the series produced on the same basis by Blanchard et al, which runs back an additional 25 years to the turn of the century. There is a distinct difference between the two series in terms of scale (largely reflecting major upward revisions to the nonresidential capital stock introduced by the BEA in 1996); but, again, in terms of the other properties of the series, both look quite similar.

Both charts provide visual evidence which strongly suggests that $q$ is a stationary process, consistent with the predictions of theory. As might be expected, however, given the well-known difficulties in testing for the presence of unit roots, statistical tests shown in Table 1 are not overwhelmingly conclusive.

Given the degree of noise and persistence in $q$, the choice of sample is fairly crucial. Using only data from 1945 onwards (the limit of availability using Federal Reserve data), it is impossible to reject a unit root on the standard ADF test. Including earlier data, the evidence for rejection becomes stronger. The table shows that extending the sample to use all available data of our own construction (running from 1925 onwards) pushes the test statistics into a zone where the null of a unit root is rejected if the statistic were normally distributed, but is marginal for a Dickey-Fuller distribution. ${ }^{14}$ If we are prepared to accept simple

\footnotetext{
${ }^{14}$ If it is assumed that, under the null, $q$ is a unit root process with zero drift, then the DickeyFuller distribution is appropriate. Since there appears no reason to impose this restriction on the null, West's (1988) result that the ADF test statistic will be asymptotically normally distributed may apply (albeit subject to the small-sample caveats of Hylleberg and Mizon (1989)). Another reason to take note of the significance levels assuming normality is to note that, if we were to assume stationarity, then the implied confidence intervals for the autoregressive parameter for $q$ lie comfortably below unity.
} 
proportional extrapolation of our data (using the definition of $q$ on Tobin's basis) using the series constructed by Blanchard et al, however, Table 1 shows that the null of a unit root is rejected fairly convincingly under both distributions. ${ }^{15}$ Table 1 also shows that truncating the sample prior to the last few years leads to a more conclusive rejection of a unit root in $q$. The impact of the last observations is thus crucial to the interpretation of the Dickey-Fuller tests. A central thrust of this paper is that the recent behaviour of $q$ is atypical, so that truncation of the sample may give a better guide.

Equally important, Monte Carlo evidence, discussed in Section 4.4, suggests that the probability of $q$ appearing to have both the observed time series properties which make it a useful valuation criterion, if the stock price were in fact a random walk is, at around 3\%, significantly lower.

A further notable feature of both definitions of $q$ is that the average values towards which the series tend to revert are less than the theoretical equilibrium value of unity. This might in part reflect any average tendency to mismeasurement of the capital stock (which will tend to be systematically overstated if, for example, the true inflation rate is less than the recorded inflation rate, or if the true rate of economic depreciation is greater than that used by the statisticians). But this alone would appear unlikely to explain such a large difference in average values. A rationale for the case in which the true equilibrium value is also less than unity may also arise from the very market inefficiency which causes stock prices to deviate from the fundamental. De Long et al's (1990) noise trader model, for example, would imply that the average ratio of the stock price to the fundamental may be below unity if stabilising "fundamentalist" investors are sufficiently risk-averse.

The third major characteristic evident in all the series shown in Charts 1 and 2 is that the most recent observation, for end-1997, is either the highest ever, or comparable to the other major peak this century, in August 1929. Using our chosen measure of $q$, with $K$ excluding land and residential housing, the unconditional probability of a higher value than the end-1997 observation is only $2 \%$, under the assumption of stationarity. This feature of the data is consistent with almost all other alternative valuation criteria, most notably the $\mathrm{P} / \mathrm{E}$ multiple and the dividend yield (for discussion of the implications of these and other alternative measures see Campbell and Shiller (1998) and Kopcke (1997))

A crucial characteristic of a stationary process is of course the ease with which

${ }^{15}$ We have thus far been unable to obtain the underlying data used in constructing Blanchard et al's series for $q$, which would enable us to produce a longer series on a more consistent basis. We hope to be able to do so in a later version of this paper. 
it can be predicted over long horizons. $q$ is a highly serially correlated, and highly noisy process, which implies that, even when the last observation is of very low unconditional probability, as at end-1997, the conditional probability of $q$ falling back over the course of the year immediately following is only around $70 \%$. But, the longer the horizon, the lower is the weight of the last observation, until, in the limit, as the horizon tends to infinity, the conditional probability of a lower value tends to the unconditional probability. Thus, the longer the horizon, the higher is the probability that $q$ will fall back over that horizon.

Of course, these univariate characteristics of $q$ need not necessarily have any implications for stock prices, and hence need not imply that $q$ is a useful valuation criterion. For this, in a multivariate context, we require the second crucial property, Granger Causality from $q$ to the stock price, and hence, implicitly, rejection of the efficient market hypothesis. To this issue we now turn.

\section{Tobin's $q$ in a Cointegrating VAR}

\subsection{Data Definitions and Univariate Properties}

Given the definition of $q$ in (3.2), and our concern to investigate the nature of Granger Causality relations, it is natural to look at a vector autoregressive representation of the following three variables: $P$ is the real share price (measured by the S\&P Industrials Index); $E$ is the stock of equities outstanding; and $W \equiv$ $K-L$ is real nonfinancial corporate net worth. $P$ and $W$ are measured in constant price terms, deflated by the US CPI; $E$ is real by construction. Continuing the convention that lower case letters represent logarithms of upper case variables, we shall model the system in terms of the vector $\mathbf{x}_{t}=\left(p_{t}, e_{t}, w_{t}\right)^{\prime}$.

Univariate $\mathrm{ADF}$ tests shown in Table 2 , for $p$, $e$ and $w$, show that a unit root in log-levels cannot be rejected for any of the variables, but is strongly rejected for all three in log-differences. We can thus be fairly confident that an I(1) representation is appropriate.

\subsection{The Reduced Rank VAR Representation}

We estimate a trivariate reduced rank VAR representation of the standard form

$$
\Delta \mathbf{x}_{t}=\boldsymbol{\psi}+\Pi \mathbf{x}_{t-1}+\varepsilon_{t}
$$

where $\boldsymbol{\psi}$ is a vector of constant terms, and (given that all three elements in $\mathbf{x}_{t}$ ) 
are $\mathrm{I}(1), \boldsymbol{\Pi}$ is assumed to be of reduced rank, $r$, and can be written as $\boldsymbol{\Pi}=\boldsymbol{\alpha} \boldsymbol{\beta}^{\prime}$, where $\alpha$ and $\boldsymbol{\beta}$ are $3 \times r$, with $\beta$ a matrix of cointegrating vectors.

Table 3 shows that model selection criteria point clearly to the optimal order of the VAR as being first order. With available data from consistent sources running from 1927 to 1997, this implies a sample period for estimation of 72 observations, from 1926 to 1997.

Table 4 shows that, analogously to the univariate case for $q$, standard tests are not overwhelmingly conclusive as to the rank of $\Pi$. The hypothesis that $\Pi$ is of rank zero can only be rejected at the $90 \%$ significance level against the alternative that it is of rank one; it is very close to rejection at the same significance level against the more general alternative that $\boldsymbol{\Pi}$ is of rank one or higher. The size of the eigenvalues, together with two out of the three usual model selection criteria, seem to point to the presence of two cointegrating relations, but essentially the data do not appear to discriminate clearly between representations with $r=1$ and $r=2$.

Due to this ambiguity we investigated the properties of both. Table 5 shows that, in the $r=2$ representation, the restriction that one of the cointegrating vectors is $(1,1,-1)$, and hence that $q$ is one of the cointegrating relations, can be easily imposed. However, imposing a representation with $r=1$, in which $q$ was the sole cointegrating relation was rejected fairly strongly. But closer examination of the two different systems (summarised in Tables 6 and 7) suggests that the rejection is largely due to the representation of $e$, the number of shares outstanding, and that the restriction impacts considerably less on the stock price equation.

Table 6 shows coefficient estimates for the $r=2$ version of the model. No restriction is imposed on the second cointegrating vector, but a just identifying restriction allows it to be represented in a form which has a zero restriction on the stock price. ${ }^{16}$ In this form the coefficient on the second cointegrating relation in the equation for $\Delta p$ is only marginally significant, but is highly significant in the equation for $\Delta e$; the reverse appears to be the case for the first cointegrating relation, $q \cdot{ }^{17}$ Given the inconclusive nature of these results, we continue to analyse both cases, but focus our discussions primarily on the more data-consistent $r=2$ case.

\footnotetext{
${ }^{16}$ In principle any linear combination of $q$ and this vector would be equally acceptable. In this form, however, the second relation appears to make some economic sense.

${ }^{17}$ Indeed, the restriction that respectively, the coefficient on $\mathrm{cr}_{2}$ in the equation for $\Delta p$, and on $q$ in the equation for $\Delta e$ are jointly zero, can easily be imposed, although we do not do so.
} 


\subsection{Tests of Granger Causality}

By the Granger Representation Theorem, the existence of cointegration must imply Granger Causality in at least one direction. As noted above, this in itself need not conflict with the random walk hypothesis, as long as Granger Causality runs from, and not to the stock price. But standard variable deletion tests, summarised in Table 8, strongly reject this version of events. Indeed, the test results are not inconsistent with unidirectional Granger Causality running in the opposite direction - implying that corporate net worth evolves as an independent unit root process. Whilst we do not impose this property, ${ }^{18}$ the contrast with the random walk case is quite marked.

This finding is however arguably broadly consistent with past literature, both testing the random walk hypothesis, and testing for the significance of Tobin's $q$ as a determinant of investment - see, for example, Blanchard et al (1993)). Indeed, the observed apparent stationarity of $q$ can only be reconciled with a weak link to investment if there is some alternative equilibrating mechanism Granger Causality to the stock price provides such a mechanism.

\subsection{Monte Carlo Analysis}

We have argued, on the basis of the results of Sections 4.5 and 4.3 that (a) there is at least one cointegrating vector between $p_{t}, e_{t}$, and $w_{t}$. (b) (one of) the cointegrating vector(s) is $(1,1,-1)$ and (c) causality runs from $q_{t}$ to $p_{t}$. This representation appears acceptable in a sequence of hypothesis tests at conventional $p$-values. Of course with a composite hypothesis of this type, and with finite samples, one is concerned about the use of asymptotic $t$ and $F$ values to assess hypotheses, and that the actual size and power of the composite hypothesis may depart from its nominal value. In this section we investigate using monte carlo techniques the probability of wrongly rejecting the null hypothesis that the stock price data were generated by an independent random walk, against our composite alternative.

\footnotetext{
${ }^{18}$ We would indeed deem it undesirable to do so. Note that the sign of coefficients on $q$ in the equations for $w$ shown in Tables 6 and 7 is consistent with Tobin's original "build-or-buy" arbitrage mechanism. And although the coefficients themselves are insignificantly different from zero at conventional levels of statistical significance, it is worth noting that the $p$-values imply a probability of $60 \%$ to $70 \%$ that the coefficients are positive, consistent with theory. It is possible that decomposing $w$ into changes in the capital stock, and in net corporate borrowing, might improve the fit of this sector of the VAR, but since this is not our primary interest, we do not pursue this here.
} 
We reestimate (4.1) imposing that stock prices are an independent random walk (i.e. setting $\alpha_{1}=0$ ), with other parameters estimated freely. We recover the variance covariance matrix and using these parameters and inital values of the data generate 10,000 replications of the three series with approriately correlated normally distributed errors. We use these generated data to investigate the probability of falsely accepting or rejecting the required hypotheses for the conclusions we set out above. Table 9 shows that in about $10 \%$ of replications an error correcting representation for $\Delta p$ driven by any linear combination of $\left(p_{t-1}, e_{t-1}, w_{t-1}\right)$ has error-correcting coefficient further from zero than that found in our data (this effectively finds a stationary combination of the $(p, e, w)$ variables with causality running to $p$ ). However, the number of replications in which the specific linear combination $q_{t}$ was stationary, with autoregressive parameter less than the estimated value implied from our original estimates of (4.1) was distinctly lower, at around $6 \%$; and the number in which both $q_{t}$ is stationary and the coefficient on $q_{t-1}$ in the error-correcting representation for $\Delta p_{t}$ is more negative than the estimate in the original system was $3 \%$. We conclude, therefore, that the the probability that the empirical evidence in favour of $q$ as a valuation criterion could have arisen by chance if prices were actually generated by an independent random walk is around $3 \% .^{19}$

\subsection{Stock Price Forecast Variance in a Cointegrating VAR}

The discussion thus far has focussed on the conditions necessary for any valuation criterion to be useful, and on the issue of whether $q$ meets these conditions. We conclude that it does. However, we have not thus far dealt with the issue raised in the introduction, which represents the primary motivation for any valuation criterion: namely, variance reduction in stock price forecasts, relative to the highly uncertain random walk case, over long horizons.

It should be obvious that any valuation measure which satisfies our two criteria must reduce the variance of stock price forecasts one step ahead - this arises directly from the properties of least squares, as long as $\alpha_{1}$ in equation (2.1) is significantly different from zero. However, the degree of improvement in predictive power over a one year horizon, whilst clearly statistically significant, is arguably not economically significant. Specifically, the unconditional standard deviation of the real stock price change over our sample was around $22.1 \%$ (and hence the sole determinant of uncertainty in the random walk representation). Whilst both

\footnotetext{
${ }^{19}$ Further details of our methodology are given in Appendix .
} 
cointegrating relations in the $r=2$ representation are statistically significant in the stock price equation, Table 7 shows that the standard error of the equation improves on the unconditional standard deviation by only just over $1 \%$ point (implying an $\bar{R}^{2}$ statistic of only 10\%). This of course should not be surprising. Whilst rejection of some form of the random walk hypothesis is a common occurrence, it is usually found that the extent of any rejection is fairly modest - our findings are consistent with this. It also implies that the deviation from textbook efficiency is plausible in terms of underlying behaviour, since the extent of the deviation translates to the incentive to engage in arbitrage to remove it. ${ }^{20}$

More than one period ahead, system properties, and hence the third property alluded to in Section 2 - essentially, the degree of predictability of the the "fundamental" - become crucial. Cointegration implies that a set of variables with, as in our case, a single stochastic trend, have forecast variances which, over sufficiently long horizons, must be dominated by the same terms (since long horizon variance is dominated by the uncertainty in the level of the stochastic trend, which is at least of the same order as the forecast horizon ${ }^{21}$, whilst the variance of the cointegrating relations goes to a finite limit). This implies that a noisy series, like the stock price may acquire, via system properties, some of the predictability of the other series in the system. The condition that this helps long-run prediction, relative to the random walk case, is ultimately that the common stochastic trend of the cointegated system should have lower variance than the stock price itself.

Appendix $C$ describes the methodology by which we derive estimates of forecast variance for the general case. This turns out to be a nontrivial exercise in the case of an integrated system. A simplified example may however help to illustrate the process.

Suppose that in equations (2.1) and(2.2) the fundamental, $f$ is an independent unit root process $\left(\beta_{1}=0\right)$, and that $\varepsilon_{t}^{p}=\varepsilon_{t}^{f}+\varepsilon_{t}^{v}$, where $\varepsilon_{t}^{f}$ and $\varepsilon_{t}^{v}$ are independent innnovations (such a system is indeed not far removed from the estimated system). The system can then be expressed in the following form:

$$
\begin{gathered}
v_{t}=\gamma_{0}+\gamma_{1} v_{t-1}+\varepsilon_{t}^{v} \\
\Delta f_{t}=\beta_{o}+\varepsilon_{t}^{f}
\end{gathered}
$$

\footnotetext{
${ }^{20}$ We discuss this issue further below in Section 7.

${ }^{21}$ We show below that if there if allowance is made for parameter uncertainty, these imply terms which are quadratic in the forecast horizon.
} 
where $v_{t}=p_{t}-f_{t}, \gamma_{0}=\alpha_{0}-\beta_{0}$, and $\gamma_{1}=1+\alpha_{1}(<1)$.

The level of $p_{T+h}$, the level of the stock price $h$ periods after the final observation, $T$, will be given by:

$$
\begin{aligned}
p_{T+h} & =f_{T+h}+v_{T+h} \\
& =f_{T}+\beta_{0} h+\sum_{j=0}^{h} \varepsilon_{T+j}^{f}+\gamma_{1}^{h} v_{T}+\sum_{j=1}^{h} \gamma_{1}^{h-j} \varepsilon_{T+j}^{v}+\sum_{j=0}^{h-1} \gamma_{1}^{j} \gamma_{0}
\end{aligned}
$$

Write $p_{T+h \mid T}$ for the optimal forecast of $p_{T+h}$ made at time $T$ (i.e.if the true model is known) and $\widehat{p}_{T+h \mid T}$ for the optimal forecats of $p_{T+h}$ made at time $T$ when one estimates parameters on the basis of information known at $T$. Then

$$
p_{T+h \mid T}=f_{T}+\beta_{0} h++\gamma_{1}^{h} v_{T}+\sum_{j=0}^{h-1} \gamma_{1}^{j} \gamma_{0}
$$

and

$$
\widehat{p}_{T+h \mid T}=f_{T}+\widehat{\beta}_{0} h+\widehat{\gamma}_{1}^{h} v_{T}+\sum_{j=0}^{h-1} \widehat{\gamma}_{1}^{j} \widehat{\gamma}_{0}
$$

where $\widehat{\beta}_{0}, \widehat{\gamma}_{0}, \widehat{\gamma}_{1}$ are estimates of $\beta_{0}, \gamma_{0}$, and $\gamma_{1}$ made on basis of information available at time $T$. Then the prediction error

$p_{T+h}-\widehat{p}_{T+h \mid T}=h\left(\beta_{0}-\widehat{\beta}_{0}\right)+\sum_{j=0}^{h} \varepsilon_{T+j}^{f}+v_{T}\left(\gamma_{1}^{h}-\widehat{\gamma}_{1}^{h}\right)+\sum_{j=1}^{h} \gamma_{1}^{h-j} \varepsilon_{T+j}^{v}+\sum_{j=0}^{h-1} \gamma_{1}^{j} \gamma_{0}-\widehat{\gamma}_{1}^{j} \widehat{\gamma}_{0}$

The variance of the prediction error for $p$ at horizon $h$ will be given by:

$$
\begin{aligned}
\operatorname{var}\left(p_{T+h}-\widehat{p}_{T+h \mid T}\right)= & h \sigma_{f}^{2}+h^{2} \operatorname{var}\left(\widehat{\beta}_{0}\right)+v_{T}^{2} \operatorname{var}\left(\widehat{\gamma}_{1}^{h}-\gamma_{1}^{h}\right) \\
& +\sum_{j=1}^{h} \gamma_{1}^{h-j} \sigma_{v}^{2}+\operatorname{var}\left(\sum_{j=0}^{h-1} \widehat{\gamma}_{1}^{h-j} \widehat{\gamma}_{0}\right) \\
& + \text { parameter covariance terms }
\end{aligned}
$$

There is a crucial dichotomy between the role of uncertainty in the fundamental, and in $v$, the valuation criterion (which might be $q$, but might equally be some alternative criterion). The variance of the fundamental has an impact which cumulates over time: one term at rate $h$, another (the impact of parameter 
uncertainty in the drift, $\beta_{0}$ ) at a rate of $h^{2}$. In contrast, whilst the terms involving uncertainty in the process determining $v$ are likely to dominate in the short run (as the one-period-ahead example illustrates), all go to finite limits, or zero, as $h$ increases. $^{22}$

Equation (4.7) also brings out the importance of the third desirable characteristic of any valuation criterion: that the fundamental be relatively predictable. The first two terms reflect the fact that any system which has a common I(1) trend must have a forecast error variance which expands indefinitely, but the rate at which it expands will be determined by $\sigma_{f}^{2}$, the uncertainty of the fundamental. ${ }^{23}$ More generally, if innovations to the fundamental are not orthogonal to those to $v$, the condition relates to the uncertainty of the stochastic trend (or trends) which drive the system.

\section{Comparing Confidence Intervals from the Cointegrating VAR and the Random Walk in Normal Circumstances: The Good News About Long-Run Stock Market Returns}

Chart 3 shows $90 \%$ confidence intervals for stock price forecasts from the version of the cointegrating VAR shown in Table 6 (with $r=2$, and $q$ as one of the cointegrating relations ${ }^{24}$ ), and from the random walk model, artificially constructed on the assumption that $q$ was at its average value at end-1997. We proceed in this way because, for the moment, we wish to focus solely on the contrast between the two models under normal circumstances, which comes down to differences between the width of the confidence intervals they generate; in the next section we shall go on to analyse the differences under the specific circumstances given by actual end-1997 values of $q$ - this in turn is driven primarily by differences between point forecasts. ${ }^{25}$

\footnotetext{
${ }^{22}$ Strictly speaking this is only the case for terms which condition on parameters. Given parameter uncertainty there must always be a non-zero probability, in a dynamic model, that the true parameters have values which imply that the process may in fact be nonstationary. Typically this problem is addressed by applying delta method approximations to the distributions of non-linear functions of parameters, assuming differentiability of the function. We apply the same technique in Appendix C.

${ }^{23}$ Since the first two terms can be simplified to the expression $\sigma_{f}^{2}\left(h+\frac{h^{2}}{T}\right)$.

${ }^{24}$ The model in Table 7 , with $r=1$, and $q$ as the sole cointegrating relation, gives results which are very similar.

${ }^{25}$ Strictly speaking it should be noted that even in normal circumstances (when $q$ is at its average value) the point forecasts of the two systems will differ, since the estimated drift parameters
} 
The extreme nature of the uncertainty surrounding the random walk forecasts is immediately evident from Chart 3 . Whilst the estimated drift pulls the confidence interval upwards over time, the degree of uncertainty surrounding the forecast increases even more rapidly, such that the $90 \%$ lower bound falls into the indefinite future. The confidence intervals are ultimately linear in the forecast horizon (due to the quadratic term in $h$ in the forecast variance - see equation 4.7), as parameter uncertainty comes to dominate all other forms of uncertainty. This linear term outweighs the impact of the drift on the lower bound. Thus there is a positive probability of real capital losses over an infinite horizon. This probability is non-trivial, at around $11 \%$. At finite horizons, this probability is distinctly larger: there is a $32 \%$ probability of real capital loss over a twenty year horizon, declining only gradually to just under $20 \%$ over a 50 year horizon.

In contrast, whilst the confidence interval generated by the cointegrating VAR is very similar to that of the random walk model over horizons of up to 2 to 3 years, this rapid expansion is driven largely by the stationary component of the forecast variance. As this tends towards its limit, the rate of increase of the confidence interval falls back to that of the stochastic trend in the system, which is clearly markedly more predictable than is the stock price. Crucially, the linear term (arising from parameter uncertainty), which ultimately drives the confidence intervals, is smaller than the drift in the stochastic trend, so that, whilst the interval continues to expand indefinitely as the horizon increases, the $90 \%$ lower bound ceases to fall after six years. Just as in the random walk case, over an infinite forecast horizon, there is a non-zero probability of capital loss, ${ }^{26}$ but this probability is trivially small. Over finite horizons, the probability of capital loss is still nontrivial, although markedly lower than in the random walk case. The probability of a real capital loss over a twenty year horizon is only $16 \%$, declining to $8 \%$ at a 30 year horizon, and less than $2 \%$ over a fifty year horizon.

This, then, is the good news about long-run stock market returns. Whilst stock market returns are clearly risky, the uncertainty surrounding these returns can be reduced signficantly by exploiting the variance reduction of the cointegrated system, such that the associated probabilities of capital loss appear considerably more in line with the "stocks for the long run" view of Siegel (1994), and the consensus view of investment practitioners.

will differ. But these differences are trivial in comparison with the differences in variance.

${ }^{26}$ Since, for any chosen level of probability, there will be an associated lower bound to the relevant confidence interval, the negative linear trend in which precisely offsets the drift in the stochastic trend. 


\section{6. .... But Circumstances are Far from Normal: The Bad News About Long-Run Stock Market Returns}

Thus far we have focussed solely on differences in forecast uncertainty between the random walk model and the cointegrating VAR. This generates solely good news for the general case, since the VAR does not significantly change the implied drift in real stock prices (and hence, for given dividend yield, the expected total return), but does reduce its variance. However, the corollary of this good news is the implication that such reduced variance can only be achieved by exploiting $q$ 's ability to forecast above-average returns when $q$ is below average, and belowaverage returns when $q$ is above average. At the time of writing, this implies distinctly bad news. ${ }^{27}$

As noted in Section 3.3, as of end-1997 $q$ was at an historically extreme value, comparable only to that seen this century in late 1929. Roughly speaking, this value implies (in point-estimate terms) a two-fold overvaluation - a figure comparable to the estimates of Campbell and Shiller (1998), using the dividend yield and the price-earnings multiple. The implication, in the context of the cointegrating VAR, is of major differences in point forecasts from the random walk model, over a large number of years. Given the differences in confidence intervals, these differences, and hence the degree of overvaluation, are also statistically significant.

Chart 4 repeats the comparative exercise of the previous chart, but feeding the end-1997 values into the system. The point forecast and confidence interval for the random walk model are of course moved by a parallel shift; but the point forecasts from the cointegrated VAR are radically different. ${ }^{28}$ Given the noisiness and persistence of the stock price there is (as was noted in the discussion of the univariate properties of $q$ in Section 3.3) a nontrivial probability that stock prices will rise in real terms, but the bulk of the interval lies below zero, and the $90 \%$ lower bound lies well below that from the random walk model for over ten years.

Chart 5 brings out the differences in implied probabilities of market falls between the two models, which cannot be read in a simple manner from Chart 4.

\footnotetext{
${ }^{27}$ As of 16 September, 1998, the Dow Jones Index stood at around 8,000, very close to its level at end-1997 - hence the degree of overvaluation, as given by $q$ was presumably very similar.

${ }^{28}$ The confidence intervals are also (marginally) wider, since one of the ways parameter uncertainty feeds into the variance calculation is a function of the extent of the deviation of the last observation from its historic average (in the illustrative example, this is equivalent to the third term in Equation (4.7)). But this term is not large, and, since it involves a term in $\gamma_{1}^{h}$ (or, in the full system, a term in $(I+\Pi)^{h}$ - see Appendix C) it also decays to zero fairly rapidly as $h$ increases.
} 
The chart shows that, using the VAR, the probability of a fall in real stock prices rises from around $70 \%$ at a one year horizon, to a peak of around $85 \%$ at a horizons of 6-8 years. Thereafter it declines only gradually: even over a thirty year horizon there is not quite an even chance of real capital gains.

It should be stressed that the model is not predicting a crash (it would arguably imply an implausible degree of violation of the principle of efficient markets if it were), but rather a prolonged period of negative price changes - a secular bear market which would unwind a significant part, but by no means all the gains seen in the secular bull market of the 1980s and 1990s. In part this profile is driven by the inevitable smoothness of econometric forecasts, but such an outcome would not in fact be out of line with past adjustments to overvalutions, which have (contrary perhaps to the general perception) also tended to be prolonged, rather than rapid. The most extreme example (and arguably not irrelevant) is that of the adjustment to the overvaluation of 1929: the real share price did not exceed its level in August 1929 (the peak) until the end of 1955, twenty-six years later. ${ }^{29}$ More recent examples - most notably that of the Japanese stock market in recent years (see French \& Poterba (1991)) - would also seem similar in nature, if not (yet) so extreme in duration.

Another way to put this in context is to note the implication of both our own estimates, based on $q$, and those of others, such as Campbell and Shiller (1998), based on other valuation criteria, that, at least as a point estimate, the US stock market is roughly twice overvalued. This is equivalent to between twenty and thirty years' worth of growth at historic average rates ${ }^{30}$ - implying that it would take this long for the real share price to regain current values, even if all of the adjustment came in the course of a single year.

Of course, these estimates are only as good as the model they are derived from. The discussion in Section 4.4 suggests that there is a non-zero probability, albeit fairly low, that our results are entirely spurious (and, of course, implicitly,

\footnotetext{
${ }^{29}$ In terms of the metric Siegel (1994) uses to assess the performance of the stock market, this statistic is unduly harsh, since it does not take into account the contribution of dividends to the total return on stocks. Probably the most favourable light which can be shed on this period would be to note that an investor only had to wait sixteen years to achieve a positive real return on stocks, compared to the peak in August 1929. He or she would also have needed to wait the same amount for an average portfolio of equities to outperform holding treasury bills, and twenty-two years to outperform government bonds.

${ }^{30}$ The lower figure is derived from the average growth rate of real share prices; the latter from the estimated growth rate of the stochastic trend in the cointegrated system. This latter is lower since it implicitly adjusts for overvaluation at the end of the sample period.
} 
those of the many other researchers who have contributed to the earlier literature we draw on). But if valuation criterion-based models are to be rejected, we must fall back on the random walk model, or some near relative thereof. But, as noted previously, in that case it is very hard to accept the idea of stocks as offering a safe long term investment (especially when indexed assets now exist). Chart 5 shows that, whilst the random walk model always offers better-than-even chances of real capital appreciation, the probability of real losses is substantial over all horizons, and actually coincides with that derived from the VAR, at a horizon of 50 years.

Hence even this possibility offers very limited reassurance. If our results are discarded, the good news, as well as the bad news, about long-run stock market returns must be discarded too: they are in effect a joint product.

\section{What do our Results Tell Us About Market Efficiency?}

We have very deliberately restricted ourselves, thus far, to noting the inconsistency of our results with the random walk representation of stock prices; we have not drawn any clear-cut conclusions as to the implications for market efficiency per se. In part this is because, as Campbell et al (op. cit.) point out, empirical tests of efficiency are so hard to interpret, since they are always tests of joint hypotheses.

Nonetheless, we feel that our results, whilst not conclusive on this issue, are at least suggestive. A logical conclusion of our results is that the predictability of returns $q$ provides, would, over sufficiently long periods, enable an investor to achieve higher average returns than if he or she simply followed the usual buyand-hold strategy. The existence of such a trading rule can be interpreted (as in Jensen (1978)) as indicative of a failure of efficiency.

One possible response to this is to assert that any apparent excess returns earned by such a trading rule are in fact illusory. This response would assert that $q$ is essentially playing the same role as the dividend yield has played in much past research, which has assumed that the power of the dividend yield in predicting returns arising from rational expectations of future time-varying expected returns.

Certainly, as we have noted, there is a clear relationship between our results and past research using both the dividend yield and the price-earnings multiple. By simple manipulation, it is straightforward to relate $q$ both to the dividend yield and to the $\mathrm{p} / \mathrm{e}$ :

$$
q=\rho \cdot P E=\frac{\rho . \pi}{D Y}
$$


where $\rho$ is the return on corporate net worth, $P E$ is the price-earnings multiple, $\pi$ is the payout ratio, and $D Y$ is the dividend yield. As noted above, the long-term instability of $\pi$ helps to explain why the dividend yield does not look stationary. But since $\rho$ and $\pi$ are relatively smooth in the short run, it is not surprising that $q$ and $D Y$ share some time series properties. Therefore, according to the logic of the time-varying expected returns hypothesis, our results could be consistent with market efficiency - any excess returns earned would precisely offset the impact of changes in the expected rate of return. On closer examination, however, it appears hard to reconcile this argument with our results, especially in the circumstances at the time of writing.

We have noted that our estimated system is currently forecasting not just low returns, but, with high probability, returns which are negative in real terms in a number of years. ${ }^{31}$ By the logic of the time-varying expected returns hypothesis, these predicted returns must be related (albeit imperfectly, since they are derived from a model which has been estimated over a finite sample - see Campbell et al, $\mathrm{Ch}$ 7) to the expected returns which are presumed to be driving the system. Hence these too must be presumed to be negative in these years.

Is it plausible that underlying expected returns should be negative? If these are being driven by deep preference parameters, it is usual to assume that stability would require that, at least in steady state, expected returns must be positive. In principle this might not rule out negative expected returns in the short term. Thus, it is (just) possible to reconcile our results for, for example, the 1970s, with time-varying expected returns. This was a period of high uncertainty, which, as a general equilibrium result, can be expected to drive down expected returns, via the precautionary motive. It was also, crucially, a period in which there existed no "safe" asset, since nominally denominated bonds and bills were subject to significant real uncertainty due to unpredictability in inflation. ${ }^{32}$

In current circumstances, however, one does not need to address the issue in terms of deep preference parameters, but simply in terms of rationality. Inflation uncertainty is currently at a very low level, so that nominally denominated assets are very much closer to being "safe" than they were in some earlier period. But in

\footnotetext{
${ }^{31}$ Although we model only the capital appreciation element, there is a high probability of capital losses which are sufficiently large that no statistically probable change in dividends could offset the impact on total real returns.

${ }^{32}$ It should be said that we are not convinced that even this argument can logically be defended on closer examination. $q$ reached a peak in the late 1960s, at which point the system was predicting negative real returns. This preceded the major macroeconomic shocks which hit in the early 1970s, which are generally assumed not to have been predicted.
} 
addition, a truly safe asset does now exist, in the form of indexed bonds, which, over a ten year horizon, offer real returns which are guaranteed to be positive. No rational investor would hold stocks which were expected to yield substantially negative returns, given the existence of an alternative asset in this form.

Do our doubts as the validity of the time-varying expected returns hypothesis therefore necessarily lead on to a rejection of efficiency as an explanation for our results? In some sense we think it must, but in asserting this, we would wish to be cautious in our use of the term "efficiency". One paradoxical aspect of the timevarying expected returns hypothesis is that, arguably, in providing an apparent reconciliation of predictability of returns with full informational efficiency, it is almost too successful, since it ignores the theoretical caveats on the limitations of feasible informational efficiency initiated by Grossman and Stiglitz (1980). The logic of this literature is that we should expect to see some breaches of full informational efficiency, as long as such breaches are not sufficiently significant that they present a clear opportunity for excess profits.

It seems to us that our results sit more easily with this conclusion, most especially when one takes into account the institutional arrangements faced by players in the financial industry. Our results imply that, for example, a pension fund manager who used a $q$-based strategy would be able to outperform his or her competitors on average. But, in a way which closely mirrors the predicament of the rational, but risk-averse investor in De Long et al's (1990) "Noise Trader" model, such a strategy would be so risky that it would be unlikely to be feasible.

We have noted that our model implied a probability of around $70 \%$ that stock prices would fall in real terms in 1998. A fund manager who believed in our results, and moved out of stocks into, for example, indexed bonds, or treasury bills, would therefore have had a $70 \%$ probability of outperforming his or her competitors. But he or she would also have faced, in so doing, a $30 \%$ probability that stocks would not fall back in real terms, and hence a not insubstantial probability that he or she would underperform competitors. For a fund manager who has gone liquid, and who is rewarded, or punished, according to relative performance, this implies a substantial probability of losing their job. ${ }^{33}$ One does not need to assume a very substantial degree of risk aversion to make this strategy deeply unattractive for the average fund manager.

Of course this argument begs the question: what drives prices sufficiently far from fundamental values that expected returns of necessity become negative?

\footnotetext{
${ }^{33}$ There have been notable examples of this occurring to fund managers who did decide to go liquid in 1997 and early 1998.
} 
We have noted that the predicament of the representative rational fund manager in 1998 was quite similar to that of the representative rational investor in the "Noise Trader" model of De Long et al (op. cit.). But this predicament only arises in that model because of the existence of agents (albeit in principle a very small number) who are not rational, an assumption which most economists must instinctively dislike. However, this assumption might also be argued not to be central to the conclusions of their model. The same results would also arise if "Noise Traders" were rational, but simply held different views. We have noted in the context of our own results the difficulties of making inferences from data in short samples; we have also noted that our results appear inconsistent with conclusions arrived at by other applied economists. If applied economists who specialise in the field are capable of drawing inferences which are inconsistent, it should hardly be surprising that non-specialists do so also - especially if the penalty for being wrong only emerges over long samples. ${ }^{34}$

Our tentative conclusion is therefore that, whilst our results do appear inconsistent with full informational efficiency, they do not obviously conflict with a more realistic notion of feasible efficiency, consistent with theory.

\section{Conclusions}

If stock prices followed a random walk, uncertainty about future stock prices would be so great that the observed bias towards equities in long-term investment portfolios would be surprising. The problem arises, essentially, because stocks are excessively volatile, compared to their fundamentals. But the source of the problem also implies a resolution. The good news about long-run stock market

\footnotetext{
${ }^{34}$ It is interesting to look at the argument presented in this section in the context of Kon-Ya, Tsutsui \& Shiller's (1998) survey of investment professionals views of the stock market. In the second half of 1997, 64.6\% of respondents felt that the US stock market was "too high" relative to fundamentals. However, lest this might appear to confirm our argument too neatly, it should also be noted thatby the first half of 1998, despite a substantial further rise in the market, this proportion had fallen back to $54.6 \%$. It is also hard to know what to make of the result that respondents in early 1998 were expecting a growth rate of the Dow Jones of $3.22 \%$. With a dividend yield roughly matching the inflation rate, this implied a total expected real return somewhat below that on indexed bonds. If one builds in a normal risk premium, this appears to suggest a modestly negative risk-adjusted excess return, which would violate rationality unless investment professionals faced some additional constraint, perhaps similar to the one we outline. However, the extent of this apparent violation is so small that it would seem likely that the average investment professional has drawn conclusions about market prospects which, whilst not optimistic, are distinctly less bearish than those our model implies.
} 
returns is that if, as a growing body of research suggests, there is even a weak tendency for stationary valuation indicators to predict future stock prices, longrun returns can become markedly more predictable. In effect, long-run stock price forecasts are long-run fundamental forecasts, plus added noise. But as long as this added noise is stationary (which is equivalent to the assumption that stock prices cannot deviate too far from the fundamental), such an approach implies that long-run returns are much less uncertain than the random walk model would imply.

We started by asking what general empirical characteristics any useful (by which we mean long-run variance reducing) valuation criterion should have. There are three such key characteristics: stationarity, Granger-causality to the stock price, and relative predictability of the fundamental (which is just the mirror image of excess volatility). Our chosen valuation criterion, Tobin's $q$ appears to possess all three characteristics, as well as having attractive theoretical properties.

We estimate a cointegrating VAR for the real stock price, the number of shares outstanding, and real corporate net worth, with Tobin's $q$ as one of the cointegrating relations. Confidence intervals for stock price forecasts generated by this system are narrower than those from the random walk model at all horizons, but most markedly at long horizons. This is the good news about long-run stock price returns, in normal circumstances.

The bad news is a corollary of the good news: current circumstances are far from normal. $q$ (along with other indicators like the dividend yield and the priceearnings multiple) pointed to massive overvaluation at end-1997, and hence the prospect of stock prices being weak in real terms, well into the next century. 


\section{Appendices}

\section{A. Data Sources and Construction}

\section{A.1. Capital Stock and Tangible Assets}

The fixed capital stock series (the nonresidential capital stock of the non-financial corporate sector) comes directly from BEA figures (Bureau of Economic Analysis, 1997) This series, which makes up the primary element of corporate net worth, is available throughout the sample period, from 1925 to 1997. It forms the core of our earlier estimates of net worth in the period before 1945. From 1945 we have estimates of inventories from the Federal Reserve (1998). Before then inventories move in line with fixed capital over the period 1925-1944.

From 1945 onwards there is an alternative source of data on tangible assets published in the Federal Reserves Balance Sheets (op. cit.), which at least in principle provide a fuller coverage, since they include estimates of land values. These figures feed into net worth calculations as published by the Federal Reserve. However, quite apart from the clear break which would arise if this series were used after 1945, but not before, there are clear discontinuities in the Fed's treatment of land in the balance sheets, even after $1945 .^{35}$

From 1956 to 1989, estimates of corporate land values, which are smooth interpolations of five-yearly observations derived from census data on taxable property values are added to BEA capital stock figures to arrive at total tangible assets. Before 1956 land values are a pure extrapolation, as a fixed share of tangible assets.

Beyond 1989, the methodology changes radically. The stock of real estate is assumed to evolve according to the following equation:

$$
\text { Stock }_{t}=\text { Stock }_{t-1} \cdot\left(R E P_{t} / R E P_{t-1}\right)+B E A \text { Net Investment in Structures }
$$

where $R E P$ is an index of corporate real estate prices. Hence the stock of land is implicitly assumed constant from 1989 onwards.

Hence until 1989 land data are independently derived, and simply added to BEA capital stock figures; thereafter they are a residual. Since there is no overlap between the real estate price index and the previous source for land values, it is

\footnotetext{
${ }^{35}$ We are grateful to Rochelle Antonimowiecz and Elizabeth Fogler of the Federal Reserve's Flow of Funds section for advising us on their methodology.
} 
impossible to check the impact of this change in methodology, but there is a clear impact on the relative magnitudes of the two stocks - indeed in some years since 1989 implicit land values have turned negative.

Nor should this be entirely surprising. The explicit methodology of the BEA approach is to value the capital stock, including structures, at replacement cost, $i e$ to evaluate the cost of building structures (suitably depreciated) from new . In contrast, valuing structures using real estate prices implicitly asks what these same structures could be sold for in the open market - this estimate of value is likely to be, and since 1989, has been, considerably more volatile.

Arguably, quite apart from problems with data consistency if land values are used, the build-or-buy arbitrage which was the original rationale for Tobin's $q$ is more consistent with the BEA approach than with the Fed's approach since 1989. By excluding land values entirely, we will clearly impart a (modest) upward bias to the average value of $q$ (offset, in practice, by other downward biases); but our methodology is otherwise equivalent to assuming land to be a constant fraction of tangible assets, which, as noted, is indeed in effect Fed practice in data between 1945 and 1956, and would, perforce, have been necessary before then.

\section{A.2. Corporate Financial Assets and Liabilities}

From 1945 onwards we use Federal Reserve figures from the flow of funds (Federal Reserve (1998), Table L102). Before 1945 an estimate can be derived indirectly from grossed-up corporate interest payments, available from the national accounts statistics (Bureau of Economic Analysis, 1992) from 1929 onwards and corporate bond yields (Ibbotson Associates (1994)). For the period 1925 to 1928, the source of data for net worth figures is even more restricted, since the data for net interest payments are only available from 1929 onwards. Over this period, therefore, we assume, for lack of better information, that net liabilities were unchanged as a proportion of net worth. In effect, therefore, over this period, changes in net worth are driven solely by changes in fixed capital.

\section{A.3. Market Value of Equities}

From 1945 onward, the numerator of $q$, the market value of corporate equities comes direct from the same source as financial assets and liabilities. This however needs to be extrapolated backwards before 1945. We have two alternative sources of data which are reassuringly similar in their implications. Using an approach similar to that applied to the construction of net liabilities data, national accounts 
data on dividend payments can be divided by the reported dividend yield (on the S\&P Industrials index). This approach is essentially that applied by Blanchard et al (1993). Since the coverage of the balance sheet figures is considerably wider than that of the $\mathrm{S} \& \mathrm{P}$ index, this approach is not perfect. An alternative data source was however provided to us by Arbor Trading, of Chicago, to whom we are extremely grateful. This series is for the market capitalisation of all listed corporations in the US, since the start of 1926. While we use the Federal Reserve figures where available, we assume that the market value of equities moves in line with the Arbor Trading series before 1945. But as Chart 2 shows, the grossing up method, as implemented by Blanchard et al, yields very similar results.

\section{B. Monte Carlo Analysis}

The procedure underlying the Monte Carlo simulations is described fairly fully in the main text: this appendix therefore only fills in remaining gaps.

One approach to the problem, very similar to that used to generate critical values for Dickey-Fuller statistics for cointegrating relationships, would have been to simulate the three series, simply assuming them to be independent univariate processes, with contemporaneous correlations and standard deviations matching the observed data. This would however have loaded the dice somewhat against the probability of observing apparent cointegration or Granger Causality. It would also have been inconsistent with the theoretical underpinnings of the efficient markets hypothesis, which would not rule out, for example, rejecting a unit root in $q$, but would simply rule out any Granger Causality to stock prices.

For this reason, the system was estimated imposing the required zero restrictions on coefficients in the equation for share prices, but allowing coefficients in the remaining two to be freely estimated: these coefficients were then used in the 10,000 simulations of artificial data. Although these coefficients were barely signficant in the case of corporate net worth, they nonetheless represent the best estimates we can arrive at, under the hypothesis that the efficient markets hypothesis is correct.

The probabilities shown in Table 9 were were based on three sets of artificial regressions, carried out on each of the 10,000 replications.

Row 1 is based on unrestricted regressions, for each replication, of the simulated share price on its own lag, and lags of the stock of equity and real net worth. The figure shown is the percentage of estimated equations in which the coefficient on the lagged share price was less than or equal to .79 (the value observed in the 
historical data). Given that, in the simulations, the true coefficient is unity, the only explanation for a figure as low as this is if there is some apparent relationship in levels between the stock price and the two remaining series.

To derive the figure in Row 2, in each simulation, an artificial series for $q$ was constructed from the three underlying artificial series. A Dickey-Fuller regression was then carried out for each replication. The figure shown is the percentage of regressions in which the estimated adjustment coefficient (the autoregressive coefficient minus one) was less than (ie, larger in absolute terms) than -0.18 , the value estimated using the historical data.

To derive the figure in Row 3 , the same series for $q$ for each replication was used in an equation in which the change in the share price was regressed on lagged $q$. The figure shown is the percentage of regressions in which the estimated coefficient was less than -0.28 , the value observed when this equation is estimated using the historical data.

\section{Calculation of Forecast Variance in a Cointegrated VAR}

Suppose the model is

$$
x_{t}=\Psi+A x_{t-1}+\varepsilon_{t} \quad t=1, \ldots T
$$

where $x_{t}$ is $g \times 1, A$ is $g \times g$ etc. Further assume

$$
E\left(\varepsilon_{t}\right)=0 \quad E\left(\varepsilon_{t} \varepsilon_{t-s}^{\prime}\right)=\Sigma \text { if } s=0
$$

For the non-stationary case with cointegration, rewrite the VAR as

$$
\begin{aligned}
\Delta x_{t} & =\Psi+(A-I) x_{t-1}+\varepsilon_{t} \\
& =\Psi+\Pi x_{t-1}+\varepsilon_{t}
\end{aligned}
$$

with cointegration we can write $\Pi=\alpha \beta^{\prime}$ with $\alpha$ and $\beta$ both $g \times r$ where $r$ is the number of cointegrating vectors.

Reimers (1995) gives a formula for forecast intervals of the levels of $x_{T+h}$ in such a system, but under the restriction that $\Psi=0$.

To allow for non-zero intercepts we write the system as

$$
\left[\begin{array}{l}
1 \\
\Delta x_{t} \\
\beta^{\prime} x_{t-1}
\end{array}\right]=\left[\begin{array}{lll}
1 & 0 & 0 \\
\Psi & \Pi & \alpha \\
0 & \beta^{\prime} & I
\end{array}\right]\left[\begin{array}{l}
1 \\
\Delta x_{t-1} \\
\beta^{\prime} x_{t-2}
\end{array}\right]+\left[\begin{array}{l}
0 \\
\varepsilon_{t} \\
0
\end{array}\right]
$$


or

$$
z_{t}=D z_{t-1}+v_{t}
$$

Now

$$
\Delta x_{t+i}=J z_{t+i}
$$

where $J=\left[0, I_{g}, 0\right]$ is a $g \times(g+r+1)$ matrix.

So

$$
\begin{aligned}
x_{T+h} & =x_{T}+\sum_{i=1}^{h} \Delta x_{T+i} \\
& =x_{T}+\sum_{i=1}^{h} J z_{T+i}=x_{T}+J \sum_{i=1}^{h}\left(D^{i} z_{T}+\sum_{j=0}^{i-1} D^{j} v_{T+i-j}\right)
\end{aligned}
$$

and also

$$
x_{T+h}=x_{T}+\sum_{i=1}^{h-1} A^{i} \Psi+\sum_{i=1}^{h-1} A^{i} \varepsilon_{T+h-i}
$$

Thus

$$
x_{T+h \mid T}=x_{T}+J \sum_{i=1}^{h} D^{i} z_{T}
$$

and

$$
\widehat{x}_{T+h \mid T}=x_{T}+J \sum_{i=1}^{h} \widehat{D}^{i} z_{T}
$$

with the same notation as previously.

Now $x_{T+h}-\widehat{x}_{T+h \mid T}=\left(x_{T+h}-x_{T+h \mid T}\right)+\left(x_{T+h \mid T}-\widehat{x}_{T+h \mid T}\right)=\sum_{i=1}^{h-1} A^{i} \varepsilon_{T+h-i}$ $+J \sum_{i=1}^{h}\left(D^{i}-\widehat{D}^{i}\right) z_{T}$.

We treat the cointegrating vectors $\beta$ as known. In the case of the first, which restricts $q$ to be one of the cointegrating relations, this is valid; for the second, estimated vector, this is a strong assumption. Reimers (1995) makes the same assumption, and provides a justification through super-consistency of estimated cointegrating parameters.

Given the assumption that we condition on the parameters in $\beta$, the only estimated parameters are in $\alpha$ and $\Psi$. Let $\delta=\left[\begin{array}{c}\operatorname{vec}(\alpha) \\ \Psi\end{array}\right]$. We have

$$
\sqrt{T}(\widehat{\delta}-\delta) \stackrel{d}{\rightarrow} N\left(0, \Sigma_{\delta}\right)
$$


Then

$$
\sqrt{T}\left(x_{T+h \mid T}-\widehat{x}_{T+h \mid T}\right) \stackrel{d}{\rightarrow} N\left[0, \frac{\partial x_{T+h \mid T}}{\partial \delta^{\prime}} \Sigma_{\delta} \frac{\partial x_{T+h \mid T}}{\partial \delta}\right]
$$

So we can approximate $m s e\left(x_{T+h \mid T}-\widehat{x}_{T+h \mid T}\right)$ by $\frac{1}{T} E\left[\frac{\partial x_{T+h \mid T}}{\partial \delta^{\prime}} \Sigma_{\delta} \frac{\partial x_{T+h \mid T}}{\partial \delta}\right]$.

Our approximation to $m s e(h)$ is then

$$
\begin{aligned}
\operatorname{mse}\left(x_{T+h}-\widehat{x}_{T+h \mid T}\right) & =\operatorname{mse}\left(x_{T+h}-x_{T+h \mid T}+x_{T+h \mid T}-\widehat{x}_{T+h \mid T}\right) \\
& =\operatorname{mse}\left(x_{T+h}-x_{T+h \mid T}\right)+m s e\left(x_{T+h \mid T}-\widehat{x}_{T+h \mid T}\right) \\
& =\sum_{j=0}^{h-1} A^{j} \Sigma A^{j}+\frac{1}{T} E\left[\frac{\partial x_{T+h \mid T}}{\partial \delta^{\prime}} \Sigma_{\delta} \frac{\partial x_{T+h \mid T}}{\partial \delta}\right]
\end{aligned}
$$

So all that is required is the evaluation of $\frac{\partial x_{T+h \mid T}}{\partial \delta}$ and $\Sigma_{\delta}$.

Now

$$
\Sigma_{\delta}=E\left[\left(\begin{array}{ll}
1 & x_{t-1}^{\prime} \beta \\
\beta^{\prime} x_{t-1} & \beta^{\prime} x_{t-1} x_{t-1}^{\prime} \beta
\end{array}\right)^{-1} \otimes \Sigma\right]
$$

and

$$
\begin{aligned}
\frac{\partial x_{T+h \mid T}}{\partial \delta} & =\frac{\partial v e c\left(J \sum_{i=1}^{h} D^{i} z_{T}\right)}{\partial \delta} \\
& =\sum_{i=1}^{h} \frac{\partial v e c\left(J D^{i} z_{T}\right)}{\partial \delta} \\
& =\sum_{i=1}^{h}\left(z_{T}^{\prime} \otimes J\right) \frac{\partial v e c\left(D^{i}\right)}{\partial \delta} \\
& =\sum_{i=1}^{h}\left(z_{T}^{\prime} \otimes J\right)\left(\sum_{j=0}^{i-1}\left(D^{\prime}\right)^{i-1-j} \otimes D^{j}\right) \frac{\partial v e c D}{\partial \delta}
\end{aligned}
$$

where

$$
D=\left[\begin{array}{lll}
1 & 0 & 0 \\
\Psi & \alpha \beta^{\prime} & \alpha \\
0 & \beta^{\prime} & I
\end{array}\right] \quad \text { and } \delta=\left[\begin{array}{c}
\operatorname{vec}(\alpha) \\
\Psi
\end{array}\right]
$$

since we condition on $z_{T}$. 


\section{Tables and Charts}

Table 1. Unit Root Tests for Tobin's q

\begin{tabular}{|c|c|c|c|c|c|}
\hline Definition & Sample & $\operatorname{ADF}(0)$ & $\operatorname{ADF}(1)$ & $\overline{\mathrm{AIC}}$ & SBC \\
\hline \multicolumn{6}{|l|}{ Tobin's Basis (Definition 3.1) } \\
\hline Inc. Land & $1947-1997$ & -0.97 & -1.03 & 1 & 0 \\
\hline Exc. Land & $1927-1997$ & $-2.09^{* *+}$ & $-2.40^{* *+}$ & 0 & 0 \\
\hline Exc. Land & $1927-1991$ & $-2.53^{* *+}$ & $-2.81^{* *+}$ & 1 & 0 \\
\hline $\begin{array}{c}\text { Exc. Land, Extrapolated back } \\
\text { Using Blanchard et al data }\end{array}$ & $1902-1997$ & $-3.64^{* *++}$ & $-2.77^{* *+}$ & 1 & 0 \\
\hline $\begin{array}{l}\text { Exc. Land, Extrapolated back } \\
\text { Using Blanchard et al data }\end{array}$ & $1902-1991$ & $-3.90^{* *++}$ & $-3.06^{* *++}$ & 1 & 0 \\
\hline \multicolumn{6}{|c|}{ Federal Reserve Basis (Definition 3.2) } \\
\hline Inc. Land & $1947-1997$ & -0.91 & -1.04 & 1 & 0 \\
\hline Exc. Land & 1927-1997 & $-2.32^{* *+}$ & $-2.75^{* *+}$ & 1 & 0 \\
\hline Exc. Land & $1927-1991$ & $-2.74^{* *+}$ & $-3.14^{* *++}$ & 1 & 0 \\
\hline
\end{tabular}

Table 2. Unit Root Tests for Underlying Data in Cointegrating VAR, 1927-1997

\begin{tabular}{|l|l|l|l|l|}
\hline Series & $\mathrm{ADF}(0)$ & $\mathrm{ADF}(1)$ & $\mathrm{AIC}$ & $\mathrm{SBC}$ \\
\hline$p$ & -0.86 & -0.99 & 0 & 0 \\
\hline$e$ & -1.97 & -1.85 & 0 & 0 \\
\hline$w$ & -0.53 & -0.52 & 1 & 1 \\
\hline$\Delta p$ & $-7.84^{*++}$ & $-7.02^{*++}$ & 1 & 1 \\
\hline$\Delta e$ & $-9.68^{*++}$ & $-6.77^{*++}$ & 1 & 1 \\
\hline$\Delta w$ & $-7.71^{*++}$ & $-4.68^{*++}$ & 1 & 0 \\
\hline
\end{tabular}

Notes to Tables 1 and 2.

$\mathrm{ADF}(0) / \mathrm{ADF}(1)$ : $\mathrm{ADF}$ Test Statistics with zero/one lag of $\Delta q$ in equation;

AIC/SBC: Optimal orders of ADF test as given by Akaike Information/ Schwarz Bayesian Criteria

**/* Rejects null at 95\%/90\% level, assuming asymptotic normality (unrestricted drift under null)

${ }^{++} /{ }^{+}$Rejects null at 95\%/90\% level, assuming Dickey-Fuller Distribution (zero drift under null) 
Table 3. Model Selection Criteria and the Order of the VAR

\begin{tabular}{|c|c|c|}
\hline \multicolumn{3}{|c|}{ Order Implied by Model Selection Criteria } \\
\hline Akaike Information Criterion & \multicolumn{2}{|c|}{1} \\
\hline Schwarz Bayesian Criterion & \multicolumn{2}{|c|}{} \\
\hline Likelihood Ratio Tests of Order Restrictions (p-values) & LR & ALR \\
\hline Order 1 vs Order 2 & 0.162 & 0.218 \\
\hline Order 0 vs Order 1 & 0.000 & 0.000 \\
\hline
\end{tabular}

Notes.

LR: Likelihood Ratio Test

ALR: Adjusted Likelihood Ratio Test

Table 4. Rank Tests

\begin{tabular}{|r|c|c|c|c|}
\hline \multicolumn{2}{|c|}{ Eigenvalues } & 0.2324 & 0.1152 & 0.0025 \\
\hline \multicolumn{5}{|c|}{ Johansen's Reduced Rank Tests } \\
\hline Null & Alternative & Test Statistic & $95 \%$ Critical Value & $90 \%$ Critical Value \\
\hline$r=0$ & $r=1$ & 19.04 & 21.12 & 19.02 \\
\hline$r \leq 1$ & $r=2$ & 8.81 & 14.88 & 12.98 \\
\hline$r \leq 2$ & $r=3$ & 0.18 & 8.07 & 6.50 \\
\hline$r=0$ & $r \geq 1$ & 28.04 & 31.54 & 28.78 \\
\hline$r \leq 1$ & $r \geq 2$ & 8.99 & 17.86 & 15.75 \\
\hline \multicolumn{2}{|c|}{$\begin{array}{r}\text { Rank implied by } \\
\text { Model Selection Criteria }\end{array}$} & AIC & SBC & HQC \\
\cline { 2 - 5 } & 2 & 0 & 2 \\
\hline
\end{tabular}

Notes.

The first three test statistics are Likelihood Ratio Tests based on the maximal eigenvalue of the Stochastic Matrix; the last two are based on the trace. Critical values are from Pesaran et al (1996)

Table 5. Restrictions on Cointegrating Vectors

\begin{tabular}{|c|c|}
\hline Restriction & Likelihood Ratio Test $(p$-value $)$ \\
\hline$q$ restriction, given $r=2$ & 0.460 \\
\hline$q$ restriction, given $r=1$ & 0.005 \\
\hline
\end{tabular}


Table 6. Coefficient Estimates and Diagnostic Statistics for the Error Correction Representation with $r=2$, and $q$ as one of the Cointegrating Relations ( $p$-values in parentheses)

\begin{tabular}{|l|l|l|l|}
\hline Equation for: & $\Delta p$ & $\Delta e$ & $\Delta w$ \\
\hline Intercept & $0.68552(0.098)$ & $0.35214(0.001)$ & $-0.028019(0.722)$ \\
\hline Coefficient on $c r_{1}(\equiv q)$ & $-0.20646(0.005)$ & $0.01947(0.266)$ & $0.014334(0.301)$ \\
\hline Coefficient on $c r_{2}$ & $-0.59124(0.076)$ & $-0.26740(0.001)$ & $0.049144(0.437)$ \\
\hline $\bar{R}^{2}$ & 0.10383 & 0.14498 & -.007228 \\
\hline Equation standard error & 0.20942 & 0.05068 & 0.040132 \\
\hline Serial Correlation $(F(1,68))$ & $0.34479(0.559)$ & $0.21773(0.642)$ & $0.33544(0.564)$ \\
\hline Normality $\left(\chi^{2}(2)\right)$ & $2.4403(0.295)$ & $1.5799(0.454)$ & $31.2511(0.000)$ \\
\hline Heteroscedasticity $(1,70))$ & $1.0672(0.305)$ & $0.02160(0.884)$ & $0.1266(0.726)$ \\
\hline Cointegrating Relations & $p$ & $e$ & $w$ \\
\hline$c r_{1}(\equiv q)$ & 1 & 1 & -1 \\
\hline$c r_{2}$ & 0 & 1 & -0.19394 \\
\hline
\end{tabular}

Table 7. Coefficient Estimates and Diagnostic Statistics for the Error Correction Representation with $r=1$, and $q$ as the Sole Cointegrating Relation ( $p$-values in parentheses)

\begin{tabular}{|l|l|l|l|}
\hline Equation for: & $\Delta p$ & $\Delta e$ & $\Delta w$ \\
\hline Intercept & $-.049215(0.233)$ & $0.019836(0.061)$ & $0.033053(0.000)$ \\
\hline Coefficient on $\mathrm{cr}_{1}(\equiv q)$ & $-0.18733(0.011)$ & $0.028122(0.131)$ & $0.012744(0.351)$ \\
\hline $\bar{R}^{2}$ & 0.074939 & 0.018464 & -0.00165 \\
\hline Equation standard error & 0.21276 & 0.054305 & 0.0400 \\
\hline Serial Correlation $(F(1,69))$ & $1.5902(0.212)$ & $2.5441(0.115)$ & $0.43386(0.512)$ \\
\hline Normality $\left(\chi^{2}(2)\right)$ & $3.6593(0.160)$ & $2.0594(0.357)$ & $36.7776(0.000)$ \\
\hline Heteroscedasticity $(1,70))$ & $1.0170(0.304)$ & $0.44788(0.506)$ & $0.1169(0.733)$ \\
\hline Cointegrating Relation $^{2}$ & $p$ & $e$ & $w$ \\
\hline$c r_{1}(\equiv q)$ & 1 & 1 & -1 \\
\hline
\end{tabular}


Table 8. Granger Causality Tests

\begin{tabular}{|l|l|l|}
\hline Block Deletion Tests in the Unrestricted Cointegrating VAR \\
\hline Hypothesis: the following variable (s) & $\ldots$. do(es) not Granger-Cause: & $p$-value \\
\hline Stock of Equities, Real Corporate Net Worth & Real Share Price & 0.009 \\
\hline Real Corporate Net Worth, Real Share Price & Stock of Equities & 0.013 \\
\hline Stock of Equities, Real Share Price & Real Corporate Net Worth & 0.454 \\
\hline Stock of Equities & Real Share Price & 0.024 \\
\hline Real Corporate Net Worth & Real Share Price & 0.003 \\
\hline
\end{tabular}

Table 9. Monte Carlo Results

\begin{tabular}{|l|l|}
\hline Implied Probabilities of Accepting Spurious Models of Share Prices \\
\hline Type of Model & Implied Probability \\
\hline Any linear combination of $p, e$, and $w$ Granger-Causes $p$ & $10.5 \%$ \\
\hline Rejection of unit root in $q$ & $6.1 \%$ \\
\hline Rejection of unit root in $q$, and Granger-Causality to Share Price & $3.1 \%$ \\
\hline
\end{tabular}




\section{References}

[1] Bekaert, G \& Hodrick, R (1992) "Characterizing Predictable Components in Excess Returns on Equity and Foreign Exchange Markets" Journal of Finance 47(2),pages 467-509.

[2] Blanchard, O J, Rhee C and Summers L (1993), "The Stock Market, Profit and Investment" Quarterly Journal of Economics, February 1993

[3] Breen, W, Glosten, L \& Jagannathan, R (1989) "Economic Significance of Predictable Variations in Stock Index Returns" Journal of Finance; 44(5), pages 1177-89.

[4] Bureau of Economic Analysis (1997) "Revisions to Tangible Assets, 19261997", Survey of Current Business, May 1997, Department of Commerce, Washington DC

[5] Bureau of Economic Analysis (1992) National Income and Product Accounts of the United States, Volume 2, 1929-1958, Department of Commerce, Washington DC

[6] Board of Governors of the Federal Reserve System (1998), Flow of Funds Accounts of the United States: Flows and Outstandings, Fourth Quarter 1997

[7] Campbell, J \& Ammer, J (1993) "What Moves the Stock and Bond Markets? A Variance Decomposition for Long Term Asset Returns", Journal of Finance 48(1), pages 3-37.

[8] Campbell J Y and Shiller R J (1998) "Valuation Ratios and the Long-Run Stock Market Outlook", Journal of Portfolio Management, Fall 1998

[9] Campbell, J, Lo, A J and MacKinlay, A C (1997), The Econometrics of Financial Markets, Princeton University Press, Princeton, NJ

[10] Chiang, R, Liu, P \& Okunev, J (1995), "Modelling Mean Reversion of Asset Prices towards Their Fundamental Value", Journal of Banking and Finance 19(8), pages 1327-40.

[11] Chopra, N, Lakonishok, J \& Ritter, J (1992), "Measuring Abnormal Performance: Do Stocks Overreact?", Journal of Financial Economics 31(2),pages 235-68. 
[12] DeBondt, W, Thaler, R (1985) "Does the Stock Market Overreact?", Journal of Finance; 40(3), July 1985, pages 793-805.

[13] De Long, J B, Shleifer, A, Summers, L H \& Waldmann, R J (1990) "Noise Trader Risk in Financial Markets", Journal of Political Economy, Vol 98, no 4, pp 703-738

[14] Fama, E \& French, K (1992) "The Cross-Section of Expected Stock Returns" Journal of Finance; 47(2), June 1992, pages 427-65.

[15] French, K R and Poterba, J M (1991) "Were Japanese Stock Prices Too High?", Journal of Financial Economics, 29 (1991) pp. 337363

[16] Grossman, S, Stiglitz, J (1980), "On the Impossibility of Informationally Efficient Markets", American Economic Review, 70(3), June 1980, pages 393408.

[17] Hayashi, F(1982), "Tobin's Marginal q and Average q: A Neoclassical Interpretation", Econometrica, 50(1), Jan. 1982, pages 213-24.

[18] Hylleberg, S \& Mizon, G (1989) "A Note on the Distribution of the Least Squares Estimator of a Random Walk with Drift", Economics Letters; 29(3), pages 225-30.

[19] Ibbotson Associates (1994), Stocks, Bonds, Bills and Inflation, Chicago, Ibbotson Associates

[20] Jegadeesh, N (1990), "Evidence of Predictable Behavior of Security Returns", Journal of Finance 45(3), pages 881-98.

[21] Jensen M C (1978) "Some Anomalous Evidence Regarding Market Efficiency", Journal of Financial Economics", Vol 6, No 2, pp 95 - 101

[22] Kopcke R W (1997)“Are Stocks Overvalued?” New England Economic Review, Federal Reserve Bank of Boston, Sept-Oct 1997

[23] Lutkepohl, H, (1991) Introduction to Multiple time series analysis,SpringerVerlag 1991

[24] Pesaran, M H, Shin Y \& Smith R J (1996), "Structural Analysis of Vector Error Correction Models with Exogenous I(1) Variables", University of Cambridge, Department of Applied Economics, Working Paper 
[25] Pesaran, M H \& Timmermann,A F (1995) "Predictability of Stock Returns: Robustness and Economic Significance" Journal of Finance; 50(4), pp 120128

[26] Poterba, J M and Summers, L H (1988), "Mean Reversion in Stock Prices: Evidence and Implications." Journal of Financial Economics vol 6 (4) pp 33364

[27] Reimers,H-E (1995) "Interval Forecasting in Cointegrated Systems" Statistical Papers 36,349-369

[28] Shiller, R (1981) "Do Stock Prices Move Too Much to Be Justified by Subsequent Changes in Dividends?" American Economic Review, LXXI, pp 421-3698

[29] Shiller, R (1998) "1929 Redux?", Intellectual Capital, http://intellectualcapital.com/issues/97/0821/icbusiness.asp.

[30] Kon-Ya, Tsutsui and Shiller (1998) "Results of Surveys about Stock Market Speculation", May 1998, http://www.econ.yale.edu/〜 shiller/investor.html

[31] Siegel, J (1994) Stocks for the Long Run, Burr Ridge, Illinois, Irwin Professional.

[32] Tobin, J (1969), "A General Equilibrium Approach to Monetary Theory" Journal of Money, Credit, and Banking, 1(1), Feb. 1969, pages 15-29.

[33] West, K (1988) "Asymptotic Normality, When Regressors Have a Unit Root", Econometrica; 56(6), November 1988, pages 1397-1417 


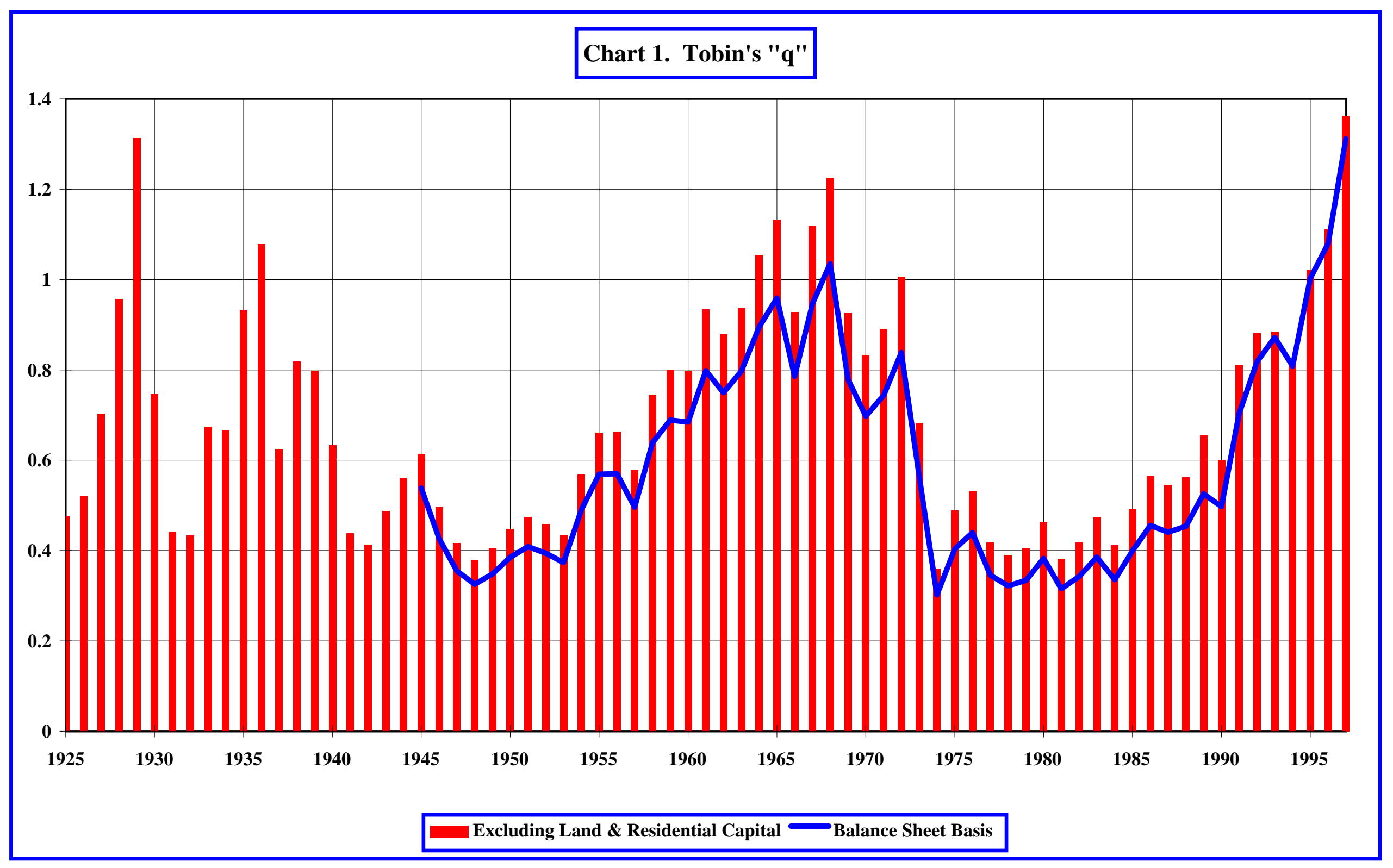




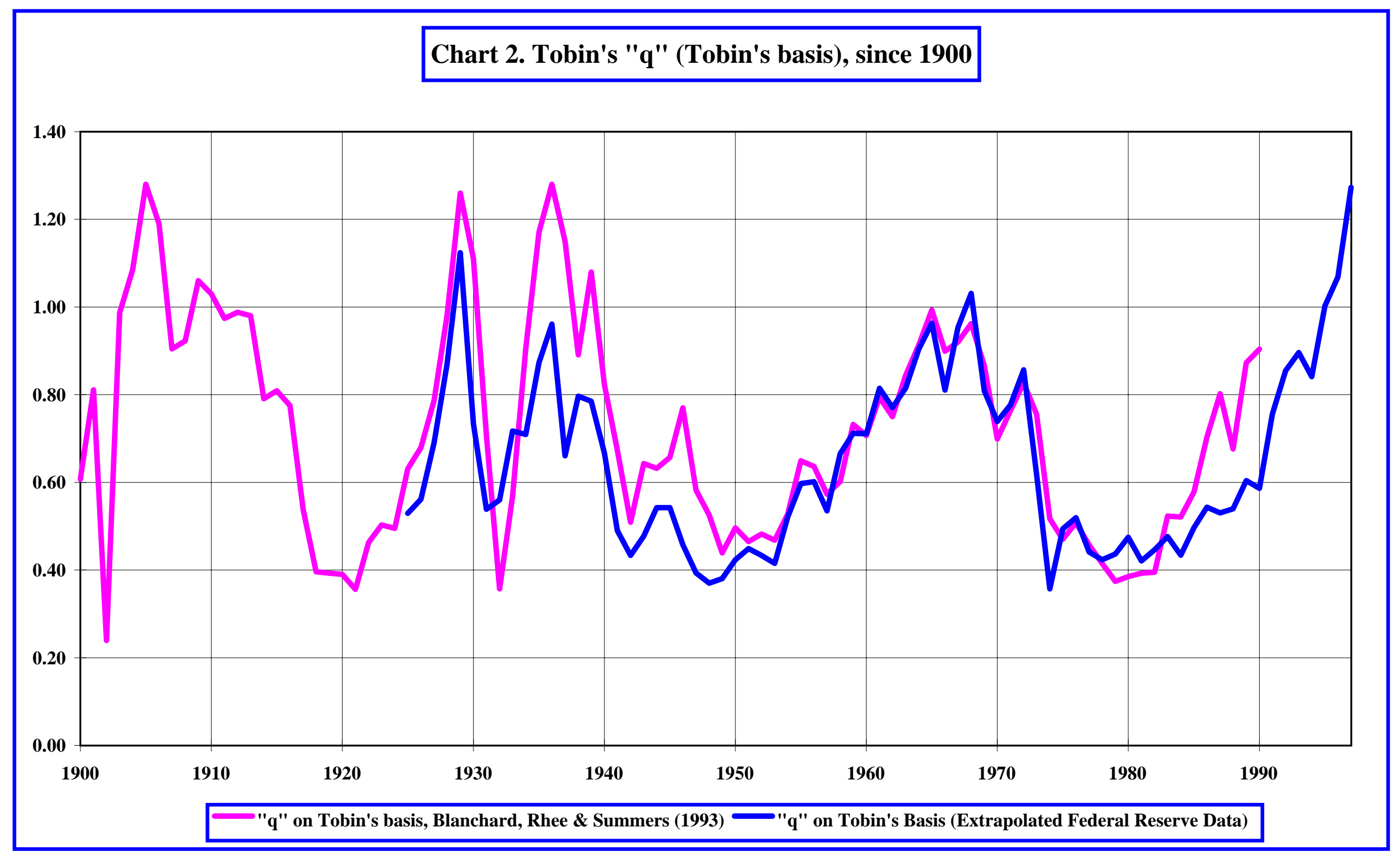




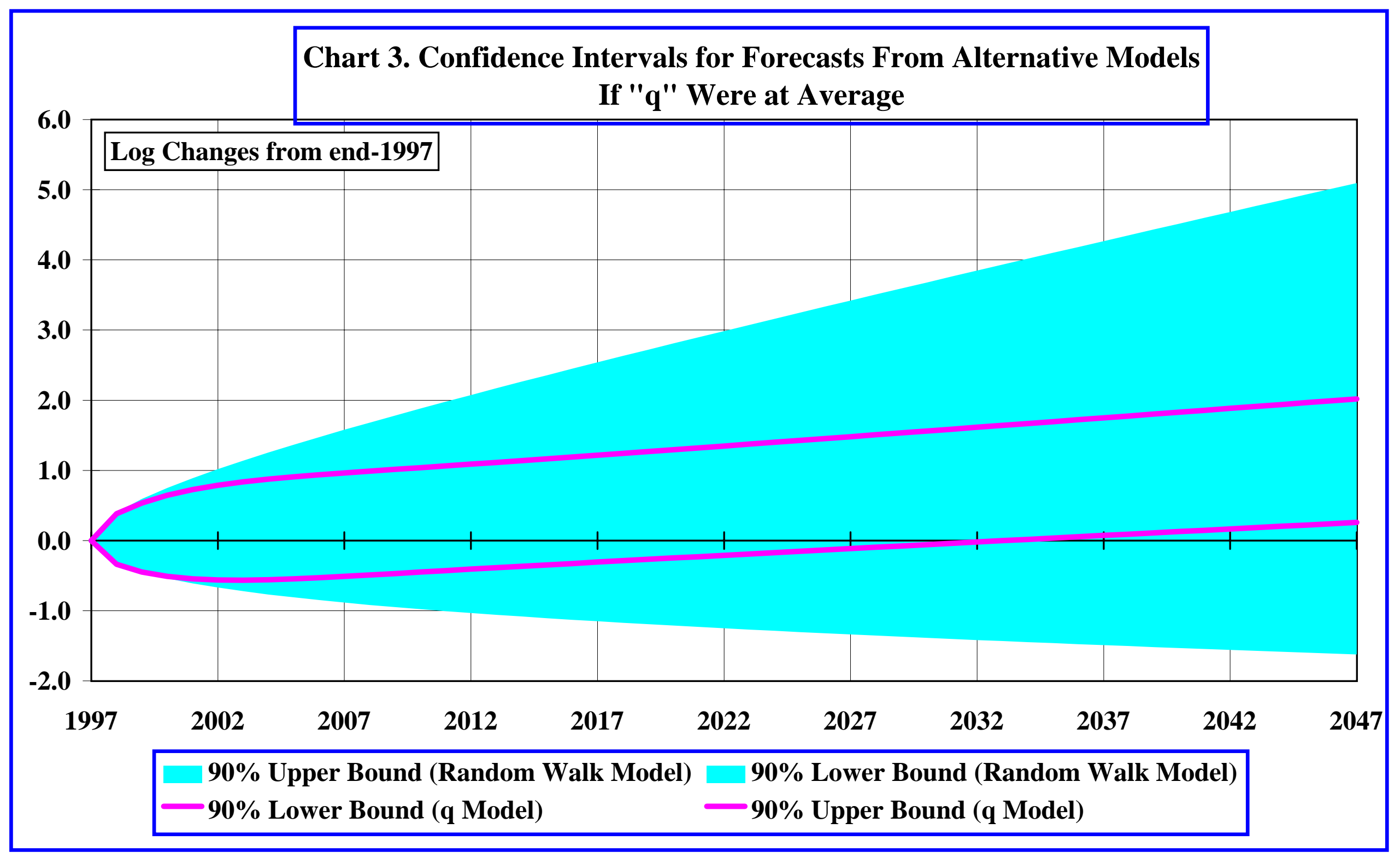




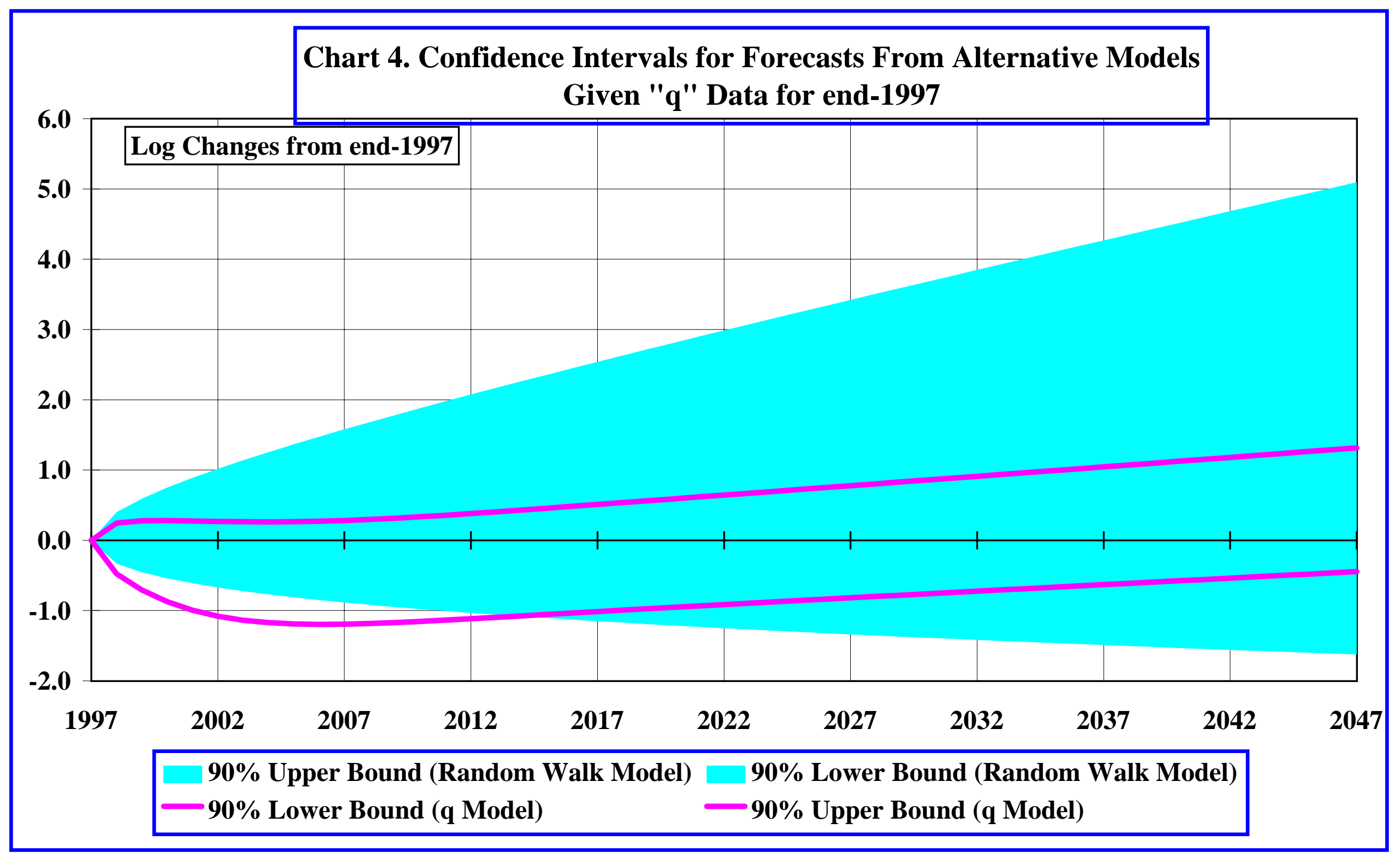




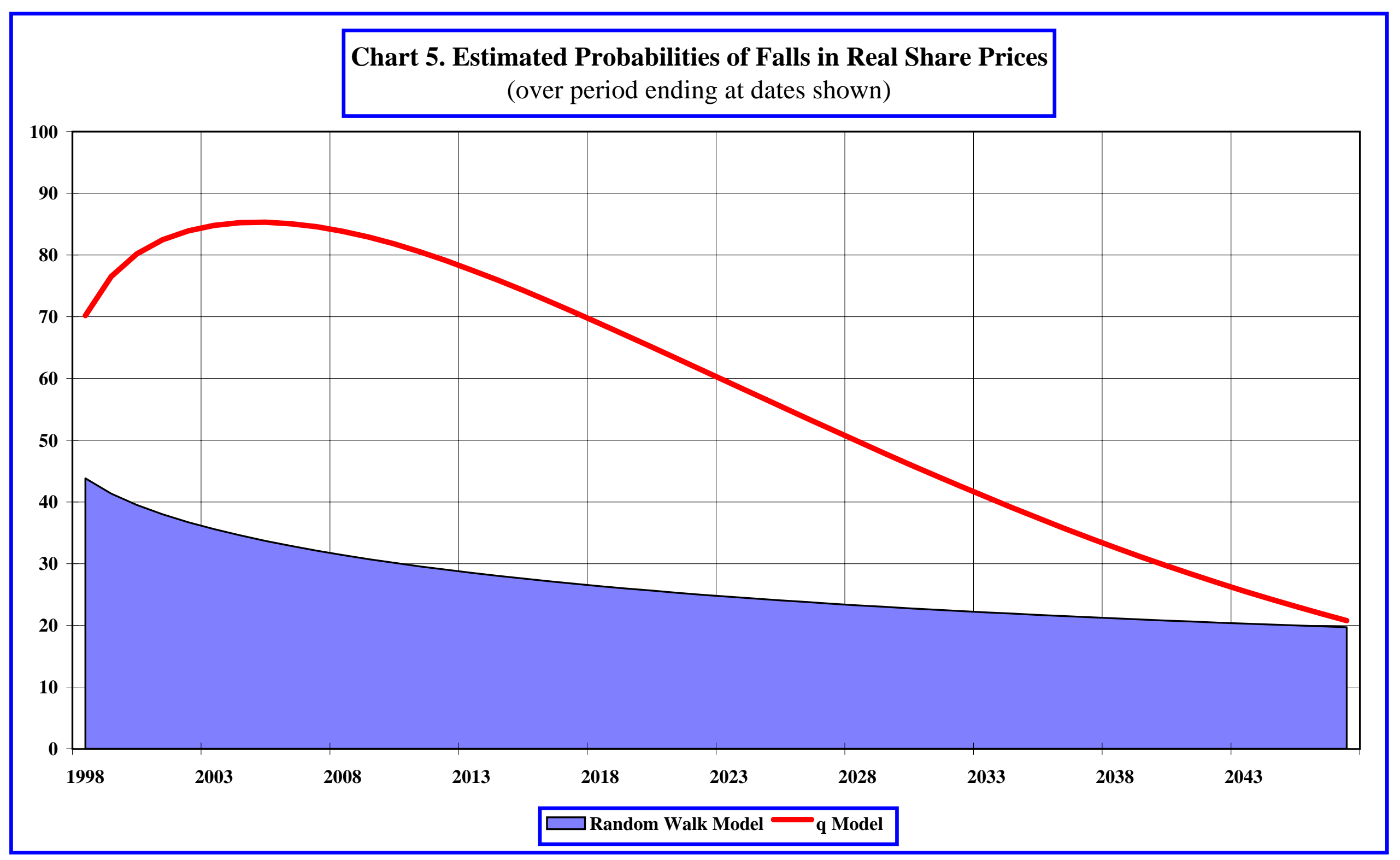

